\title{
Statistical Methods and Software for the Analysis of Occupational Exposure Data with Non-Detectable Values
}

SEPTEMBER 2005

Prepared by

E. L. Frome

Computer Science and Mathematics Division

Oak Ridge National Laboratory

Paul F. Wambach

U. S. Department of Energy 


\title{
DOCUMENT AVAILABILITY
}

Reports produced after January 1, 1996, are generally available free via the U.S. Department of Energy (DOE) Information Bridge:

Web site: http://www.osti.gov/bridge

Reports produced before January 1, 1996, may be purchased by members of the public from the following source:

\author{
National Technical Information Service \\ 5285 Port Royal Road \\ Springfield, VA 22161 \\ Telephone: 703-605-6000 (1-800-553-6847) \\ TDD: $703-487-4639$ \\ Fax: 703-605-6900 \\ E-mail: info@ntis.fedworld.gov \\ Web site: http://www.ntis.gov/support/ordernowabout.htm
}

Reports are available to DOE employees, DOE contractors, Energy Technology Data Exchange (ETDE) representatives, and International Nuclear Information System (INIS) representatives from the following source:

Office of Scientific and Technical Information

P.O. Box 62

Oak Ridge, TN 37831

Telephone: 865-576-8401

Fax: $865-576-5728$

E-mail: reports@adonis.osti.gov

Web site: http://www.osti.gov/contact.html

This report was prepared as an account of work sponsored by an agency of the United States Government. Neither the United States government nor any agency thereof, nor any of their employees, makes any warranty, express or implied, or assumes any legal liability or responsibility for the accuracy, completeness, or usefulness of any information, apparatus, product, or process disclosed, or represents that its use would not infringe privately owned rights. Reference herein to any specific commercial product, process, or service by trade name, trademark, manufacturer, or otherwise, does not necessarily constitute or imply its endorsement, recommendation, or favoring by the United States Government or any agency thereof. The views and opinions of authors expressed herein do not necessarily state or reflect those of the United States Government or any agency thereof. 
STATISTICAL METHODS AND SOFTWARE FOR THE ANALYSIS OF OCCUPATIONAL EXPOSURE DATA WITH NON-DETECTABLE VALUES

\author{
Edward L. Frome \\ Computer Science and Mathematics Division \\ Oak Ridge National Laboratory \\ Paul F. Wambach \\ U. S. Department of Energy
}

Date Published: September 2005

\author{
Prepared by \\ OAK RIDGE NATIONAL LABORATORY \\ P. O. Box 2008 \\ Oak Ridge, Tennessee 37831-6285 \\ managed by \\ UT-Battelle, LLC \\ for the \\ U.S. DEPARTMENT OF ENERGY \\ under contract DE-AC05-00OR22725
}




\section{CONTENTS}

Page

ABSTRACT

iii

1. INTRODUCTION

2. STATISTICAL ANALYSIS FOR COMPLETE SAMPLES ................... 2

2.1 CONFIDENCE LIMITS FOR THE MEAN EXPOSURE LEVEL ............ 3

2.2 CONFIDENCE LIMIT FOR PTH PERCENTILE ......................... 3

2.3 CONFIDENCE LIMITS FOR EXCEEDANCE FRACTION................... 4

3. ANALYSIS OF DATA WITH NON-DETECTS ............................. 5

3.1 MAXIMUM LIKLIHOOD ESTIMATEION FOR LOGNORMAL DATA

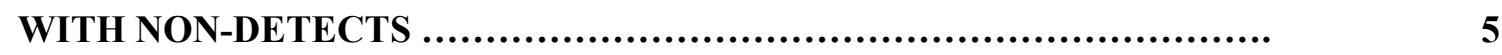

3.2 CONFIDENCE LIMITS FOR THE MEAN EXPOSURE LEVELS

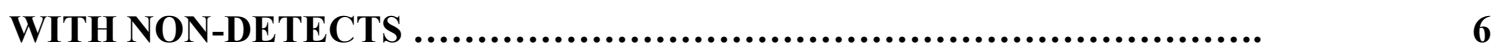

3.3 CONFIDENCE LIMITS FOR THE PTH PERCENTILE WITH

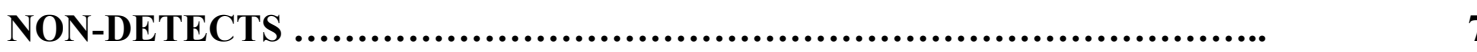

3.4 CONFIDENCE LIMITS FOR EXCEEDANCE FRACTIONS

WITH NON-DETECTS..................................................

3.5 NON-PARAMETRIC METHODS FOR SAMPLES WITH

NON-DETECTS.........................................................

3.6 NON-PARAMETRIC UPPER TOLERANCE LIMIT AND

EXCEEDANCE FRACTION................................................ 9

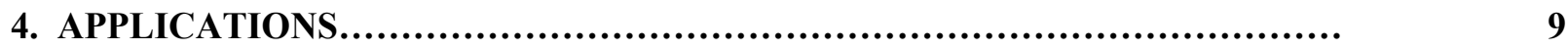

4.1 EXAMPLE 1. SURFACE WIPE SAMPLES FROM ELEVATED .......... 10 SEMELTER SURFACES

4.2 EXAMPLE 2. TWA BERYLLIUM EXPOSURE DATA ...................... 12

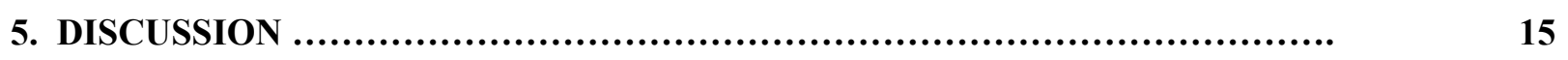

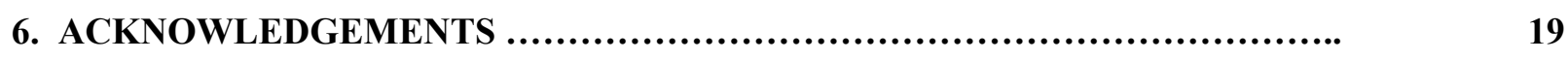

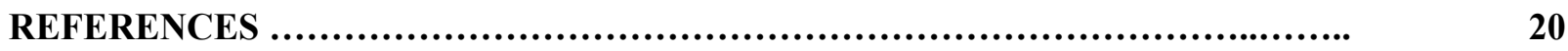

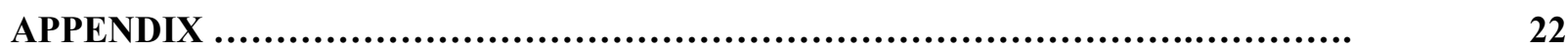




\begin{abstract}
Environmental exposure measurements are, in general, positive and may be subject to left censoring; i.e,. the measured value is less than a "detection limit." In occupational monitoring, strategies for assessing workplace exposures typically focus on the mean exposure level or the probability that any measurement exceeds a limit. Parametric methods used to determine acceptable levels of exposure, are often based on a two parameter lognormal distribution. The mean exposure level, an upper percentile, and the exceedance fraction are used to characterize exposure levels, and confidence limits are used to describe the uncertainty in these estimates. Statistical methods for random samples (without non-detects) from the lognormal distribution are well known for each of these situations. In this report, methods for estimating these quantities based on the maximum likelihood method for randomly left censored lognormal data are described and graphical methods are used to evaluate the lognormal assumption. If the lognormal model is in doubt and an alternative distribution for the exposure profile of a similar exposure group is not available, then nonparametric methods for left censored data are used. The mean exposure level, along with the upper confidence limit, is obtained using the product limit estimate, and the upper confidence limit on an upper percentile (i.e., the upper tolerance limit) is obtained using a nonparametric approach.

All of these methods are well known but computational complexity has limited their use in routine data analysis with left censored data. The recent development of the $\mathrm{R}$ environment for statistical data analysis and graphics has greatly enhanced the availability of high-quality nonproprietary (open source) software that serves as the basis for implementing the methods in this paper. Numerical examples are provided and $\mathrm{R}(2004)$ functions are available at the analysis of occupational exposure data web site http://www.csm.ornl.gov/esh/aoed/ (AOED).
\end{abstract}

Key words: exposure measurements, lognormal, maximum likelihood, left censored, non-detect, confidence limits, tolerance limit, exceedance fraction, occupational monitoring. 


\section{INTRODUCTION}

Regulatory and advisory criteria for evaluating the adequacy of occupational exposure controls are generally expressed as limits that are not to be exceeded in a work shift or shorter time-period if the agent is acutely hazardous. Exposure monitoring results above the limit require minimal interpretation and should trigger immediate corrective action. Demonstrating compliance with a limit is more difficult. The American Industrial Hygiene Association (AIHA) has published a consensus standard with two basic strategies for evaluating an exposure profile [Mulhausen and Damiano (1998)]. The first approach is based on the mean of the exposure distribution, and the second approach considers the "upper tail" of the exposure profile. Statistical methods for estimating the mean, an upper percentile of the distribution, the exceedance fraction, and the uncertainty in each of these parameters are described. Most of the AIHA methods are based on the assumptions that the exposure data does not contain non-detects, and that a lognormal distribution can be used to describe the data. Exposure monitoring results from a compliant workplace tend to contain a high percentage of non-detected results when the detection limit is close to the exposure limit, and in some situations, the lognormal assumption may not be reasonable. There are parametric methods for censored lognormal data and non-parametric methods that can be used with left censored data to calculate all of the statistics recommended by the AIHA for the complete data case. However, the only practical way to compute these statistics is with statistical software. The recent availability of free, high-quality statistical software means that complex calculations are no longer a barrier to the statistical analysis of almost any occupational exposure data set. This also eliminates the need for special tables and graphical methods that are used in the complete data case for the lognormal distribution.

Statistical methods for the analysis of right censored data using various parametric and non-parametric methods are well known and generally referred to as "survival analysis" [Cox and Oakes (1984) or Kabfleish and Prentice (1980)]. In this situation, the dependent or response variable (say T) is usually time to the occurrence of event; i.e., the "survival time" (or time to failure) of an observational or experimental unit (e.g., animal, person, or machine). T may be referred to as a "lifetime random variable" and is by definition positive, and may be subject to "censoring." As a typical example, let $\mathrm{T}_{\mathrm{i}}$ represent the survival time of the $i$ th patient in a clinical trial. If the trial ends and the patient is not known to have "failed" the observed survival time, say $t_{i}^{*}$, is right censored (i.e., it is only known that $T_{i}$ is greater than $\mathrm{t}_{\mathrm{i}}^{*}$ ). This can occur for several reasons. Suppose, for example, that all patients enter the trial at the same time and are followed until a specified end date, then those individuals still at risk have a censored survival time that is the same for all surviving patients (Type I censoring). If patients enter the trial at random and the trial ends at a fixed date, then the value of $t_{i}^{*}$ is different for each surviving patient (random censoring). Statistical methods for the analysis of right censored data are widely used and computer software for survival analyses is available in most general purpose statistical programs (e.g., the R survival library).

In this report, the dependent or response variable of interest is the amount, say X, of a measured quantity. $\mathrm{X}$ is a positive random variable and as the result of the analytic methods used, the observed value for the $i$ th measurement may be reported as (left) "censored" and is referred to as a non-detect or as being less than a "detection limit"(DL) say $x_{i}^{*}$ (i.e., it is only known that $X_{i}$ is less than $x_{i}^{*}$ ). A frequent assumption is that the distribution of $X$ is lognormal. See Aitchison and Brown(1969) and Crow and Shimizu(1988) for general treatment of the lognormal distribution and its application. Schmoyer et. al. (1996) considered the lognormal model for contaminant concentrations in environmental risk assessment for both complete and left censored samples. Akritas et. al. (1994) provide a detailed discussion of various methods that have been proposed for parameter estimation for left censored data. Methods were classified into three general areas as described by Helsel (1990). They are: (1) simple substitution; e.g., replace a censored observation with one-half of its value; (2) parametric methods; e.g., censored data maximum likelihood (ML), and (3) "robust parametric methods" based on variations of "probability plot 
regression." Simulations studies have been done to compare these methods under various conditions with the primary focus on bias and mean square error of location and scale parameters [see Helsel and Cohen(1988), Newman et. al. (1989)]. Akritas et. al. (1994) have reviewed these and other studies, and note that ML methods under the lognormal model provide expressions for the variance of the parameter estimates. This is important when an upper percentile, say Xp , of the exposure distribution is of interest. For example, the ML estimate of $\log \left(\mathrm{X}_{\mathrm{p}}\right)$ is a linear combination of the lognormal parameters, and the standard error of this quantity can be estimated from the ML parameter covariance matrix. Consequently, confidence limits for both $X_{p}$ and the exceedance fraction can be obtained using the ML approach. Taylor et. al. (2001) have noted that regarding all non-detected values as censored outcomes from a lognormal distribution may not always be appropriate. If there is reason to believe that a non-negligible proportion of the non-detects are "true zero" exposures, then a censored lognormal mixture model (a zeroinflated lognormal model with censoring) should be considered. ML methods for estimation and hypothesis testing are described and the relationship between ML parameter estimates from the mixture model and those based on either a left truncated or censored lognormal model are described. Moulton and Halsey(1995) emphasize that it is also possible that non-detects may be from a second (possibly lognormal) distribution rather than a point mass at zero. Fowlkes (1979) has described methods for studying the mixture of two lognormal distributions, although he did not consider left censored data. In situations where the lognormal model (or some other distribution such as the gamma or Weibull) is not reasonable, a non-parametric approach can be used. All of the methods just described can be implemented using R, the ML method being the most difficult. It is also possible to develop procedures for all of these methods in several proprietary statistical programs that are available commercially.

In the discussion that follows the generic term "acceptable" refers to the situation where the distribution of the exposure measurement $X$ satisfies a specified criteria indicating, for example, that the workplace is "safe," or that the surfaces of a survey unit are "clean." The term survey unit describes all or part of an entity (e.g., building, piece of equipment) that is being evaluated. The term "unacceptable" means that the distribution of the exposure measurements indicates that the workplace or survey unit is "contaminated" or "hazardous." The formal statistical procedures used to demonstrate that an exposure distribution is acceptable is to state a null hypothesis in the form $\mathrm{H}_{0}: \theta \geq \mathrm{L}$, where $\theta$ represents a parameter of the exposure distribution (e.g., the mean, a percentile, or the exceedance fraction), and $\theta \geq \mathrm{L}$ indicates that the exposure distribution is unacceptable. Then, based on a random sample from the exposure distribution, an estimate of $\theta$ and an upper confidence limit (UCL) with a specified confidence level, say $\gamma$, are calculated. If the $100 \gamma \% \mathrm{UCL}$ is less than $\mathrm{L}$, then the null hypothesis is rejected and the exposure distribution is acceptable. A Type I error occurs if $\mathrm{H}_{0}$ is rejected when it is true (i.e., the $\mathrm{X}$ distribution is incorrectly considered to be acceptable). This will occur with a probability (type I error rate) that is less than or equal to $\alpha=(1-\gamma)$, with $\alpha=1-\gamma$ when $\theta=\mathrm{L}$. These and other related procedures are described in detail in an occupational exposure context by Mulhausen and Damiano (1998).

\section{STATISTICAL ANALYSIS FOR COMPLETE SAMPLES}

Lyles and Kupper (1996) have discussed strategies for the assessment of workplace exposures using timeweighed average (TWA) exposure measurements on a representative sample of workers as a typical example. The TWA measurements are considered to be a random sample from a lognormal distribution without censoring. They describe "exact" statistical methods for testing either (1) the null hypothesis that the mean exposure level for a similar exposure group is below a certain limit; i.e., the long-term average permissible exposure limit, or (2) that a specified percentile of the $\mathrm{X}$ distribution does not exceed a limit L. To review what is known for the complete data case suppose that $x_{i}, i=1, \ldots, n$ is a random sample from a lognormal distribution with mean $\mu_{\mathrm{x}}=\exp \left(\mu_{\mathrm{y}}+\sigma_{\mathrm{y}}^{2} / 2\right)$, where $\mu_{\mathrm{y}}$ and $\sigma_{\mathrm{y}}^{2}$ are the corresponding 
mean and variance of $\mathrm{y}_{\mathrm{i}}=\log \left(\mathrm{x}_{\mathrm{i}}\right)$. Let $\overline{\mathrm{y}}=\Sigma_{\mathrm{i}} \mathrm{y}_{\mathrm{i}} / \mathrm{n}$ and $\mathrm{s}_{\mathrm{y}}^{2}=\Sigma\left(\mathrm{y}_{\mathrm{i}}-\overline{\mathrm{y}}\right)^{2} /(\mathrm{n}-1)$ where $\mathrm{s}_{\mathrm{y}}^{2}$ is the unbiased estimator for $\sigma_{\mathrm{y}}^{2}$.

\subsection{CONFIDENCE LIMITS FOR THE MEAN EXPOSURE LEVEL}

A number of methods have been proposed for calculating confidence limits for $\mu_{\mathrm{x}}$ [e.g., Armstrong (1992)]. For Land's (1972) exact method the 100 \% UCL is exp $\left[\left(\bar{y}+1 / 2 s_{y}^{2}+C s_{y} / \sqrt{ }(n-1)\right]\right.$, where C depends on $s_{y}, n$, and $\alpha$ and requires special tables. This is the "best" ( i.e., uniformly most powerful unbiased test) for complete samples. The $100 \gamma \%$ lower confidence limit (LCL) is obtained in a similar way. The two one-sided limits can be combined to obtain an approximate confidence interval. It is also possible to obtain an exact two-sided confidence interval using Land's exact method. The "best estimate" of $\mu_{\mathrm{x}}$ in complete samples is the minimum variance unbiased estimate [see Hewett and Ganser (1997) for details]. Equivalent optimal methods for randomly left censored data have not been developed. Two approximate confidence limits described by Land (1972) for the complete data case can be used for left censored data.

The first method is attributed to D.R. Cox and is based on calculating an estimate of $\varphi=\log \left(\mu_{x}\right)=$ $\mu_{\mathrm{y}}+\sigma_{\mathrm{y}}^{2} / 2$. For the complete data case the minimum variance unbiased estimate of $\varphi$ is $\widetilde{\varphi}=\overline{\mathrm{y}}+\mathrm{s}_{\mathrm{y}}^{2} / 2$, and the variance of $\tilde{\varphi}$ is $\operatorname{var}(\tilde{\varphi})=\operatorname{var}(\overline{\mathrm{y}})+1 / 4 \operatorname{var}\left(\mathrm{s}_{\mathrm{y}}^{2}\right)=\mathrm{s}_{\mathrm{y}}^{2} / \mathrm{n}+1 / 2 \mathrm{~s}_{\mathrm{y}}^{4} /(\mathrm{n}-1)$. The $100 \gamma \%$ UCL for $\mu_{\mathrm{x}}$ is $\exp \left[\widetilde{\varphi}+\mathrm{t} \operatorname{var}(\tilde{\varphi})^{1 / 2}\right]$, and the $100 \gamma \% \mathrm{LCL}$ for $\mu_{\mathrm{x}}$ is $\exp \left[\widetilde{\varphi}-\mathrm{t} \operatorname{var}(\widetilde{\varphi})^{1 / 2}\right]$, where $\mathrm{t}=\mathrm{t}(\gamma, \mathrm{n}-1)$ is the $100 \gamma$ percentage point of Student's t distribution on n-1 degrees of freedom [Land (1972) and Armstrong (1992)]. The point estimate of $\mu_{\mathrm{x}}$ for this method is $\exp (\widetilde{\varphi})$. These estimates can be viewed as "bias adjusted" ML estimates, since the ML estimate of $\varphi$ is $\hat{\varphi}=\hat{\mu}_{\mathrm{y}}+\hat{\sigma}_{\mathrm{y}}{ }^{2} / 2$, and its variance is estimated as $\operatorname{var}(\hat{\varphi})=\hat{\sigma}_{\mathrm{y}}{ }^{2} / \mathrm{n}+\hat{\sigma}_{\mathrm{y}}{ }^{4} /(2 \mathrm{n})$ where $\hat{\sigma}_{\mathrm{y}}{ }^{2}=\Sigma\left(\mathrm{y}_{\mathrm{i}}-\overline{\mathrm{y}}\right)^{2} / \mathrm{n}$. The ML estimate of the (arithmetic) mean of $\mathrm{X}$ is $\hat{\mu}_{\mathrm{x}}=\exp (\hat{\varphi})$. The estimate of the $100 \gamma \% \mathrm{UCL}$ is $\exp \left[\hat{\varphi}+\mathrm{t} \operatorname{var}(\hat{\varphi})^{1 / 2}\right]$, and the estimate of the $100 \gamma \% \mathrm{LCL}$ is $\exp \left[\hat{\varphi}-\mathrm{t} \operatorname{var}(\hat{\varphi})^{1 / 2}\right]$. For left censored data ML estimates of the above quantities are not available in closed form, but can be obtained numerically (Cohen, 1991). The bias adjustment of variance terms described above could be applied to the censored data ML estimates so that results will reduce to the complete data case as the proportion of non-detects goes to zero. The second approximate method for confidence limits for $\mu_{\mathrm{x}}$ is obtained by calculating the sample mean $\overline{\mathrm{x}}$ as the point estimate of $\mu_{\mathrm{x}}$ and the approximate lower and upper limits are $\bar{x} \pm t(\gamma, n-1) s_{x} / V_{n}$, where $s_{x}^{2}=\Sigma_{i}\left(x_{i}-\bar{x}\right)^{2} /(n-1)$. The central limit theorem implies that this method should converge to the exact limit as $\mathrm{n}$ becomes large. For left censored data the product limit estimate (PLE) (Schmoyer et al, 1996) is used to obtain a non-parametric estimate of $\overline{\mathrm{x}}$ and approximate confidence limits for $\mu_{\mathrm{x}}$ (see Section 3.5).

\subsection{CONFIDENCE LIMIT FOR THE PTH PERCENTILE}

Let $X_{p}$ denote the 100 pth percentile of the lognormal distribution. The point estimate is $x_{p}=\exp \left(\bar{y}+z_{p}\right.$ $\mathrm{s}_{\mathrm{y}}$ ) where $\mathrm{z}_{\mathrm{p}}$ is the pth quantile of the standard normal distribution. An exact $100 \gamma \%$ upper confidence limit for the pth percentile is $\operatorname{UX}(p, \gamma)=\exp \left(\bar{y}+K s_{y}\right)$ and is referred to as the upper tolerance limit. The value of $\mathrm{K}$ depends on $\mathrm{n}, \mathrm{p}$, and $\gamma$ and is obtained from the $100 \gamma$ percentile of the noncentral $\mathrm{t}$ distribution with n-1 degrees of freedom and noncentrality parameter $-\sqrt{ } n z_{p}$ [Lyles and Kupper (1996); 
Johnson and Welch (1940)]. The null hypothesis of interest is $\mathrm{H}_{0}: \mathrm{X}_{\mathrm{p}} \geq \mathrm{L}_{\mathrm{p}}$ where $\mathrm{L}_{\mathrm{p}}$ is a specified limit (e.g., the occupational exposure limit). If $\mathrm{UX}(\mathrm{p}, \gamma)<\mathrm{L}_{\mathrm{p}}$ then $\mathrm{H}_{0}$ is rejected indicating that the exposure level is acceptable (i.e, workplace is "safe" or object is "clean"). In this situation the probability is $\gamma$ (we are $100 \gamma \%$ confident) that at least $100 \mathrm{p} \%$ of the $\mathrm{X}$ values are less than $\mathrm{UX}(\mathrm{p}, \gamma)$ which is less than $\mathrm{L}_{\mathrm{p}}$. Throughout this report, reference to an $\mathrm{R}$ function is indicated by bold face font. The $\mathrm{R}$ function extol(n,p,gam) (see the Appendix) will return the one-sided tolerance factor $\mathrm{K}$ for any reasonable values of $n, p$, and $\gamma$. Further, extol(n,p,1-gam) will return the factor $\mathrm{K}^{\prime}$ proposed by Tuggle (1982) that can be used to calculate the exact $100 \gamma \%$ lower confidence limit for the pth percentile $\operatorname{LX}(\mathrm{p}, \gamma)=\exp \left(\overline{\mathrm{y}}+\mathrm{K}^{\prime} \mathrm{s}_{\mathrm{y}}\right)$.

If $\operatorname{LX}(p, \gamma)>\mathrm{L}_{\mathrm{p}}$ the probability is $\gamma$ that at least $100(1-\mathrm{p}) \%$ of the $\mathrm{Xs}$ are above $\mathrm{L}_{\mathrm{p}}$. The one-sided tolerance bounds can be combined to obtain an approximate two-sided tolerance interval which is a confidence interval for $X_{p}$. Hahn and Meeker (1991) discuss the relationship between exact one and twosided tolerance bounds, confidence intervals for population percentiles, and other types of statistical intervals. The factors $\mathrm{K}$ and $\mathrm{K}^{\prime}$ obtained using extol are found in their Table A.12 for selected values of $\mathrm{n}, \mathrm{p}$, and $\gamma$ and in Mulhausen and Damiano(1998) Appendix Table VII..

\subsection{CONFIDENCE LIMITS FOR EXCEEDANCE FRACTION}

Let $F_{L}$ represent the proportion of the $\mathrm{Xs}$ that exceed a given limit $\mathrm{L}_{\mathrm{p}}$. The null hypothesis is $\mathrm{H}_{0}: \mathrm{F}_{\mathrm{L}} \geq \mathrm{F}^{0}$ $=1$-p; i.e., $\mathrm{F}_{0}$ is the maximum proportion of the population that can exceed the limit $\mathrm{L}_{\mathrm{p}}$. The point estimate of $F_{L}$ is $f=1-N(u)$, where $u=\left[\log \left(L_{p}\right)-\bar{y}\right] / s_{y}$ and $N(u)$ is the standard normal distribution function. If the $100 \gamma \% \mathrm{UCL}$ for $\mathrm{F}_{\mathrm{L}}, \mathrm{Uf}\left(\mathrm{L}_{\mathrm{p}}, \gamma\right)$, is less than $\mathrm{F}_{0}$ than $\mathrm{H}_{0}$ is rejected (i.e. the object or workplace is acceptable). This limit is obtained by first calculating the $100 \gamma \%$ lower confidence limit for $\mathrm{u}$. It can be shown that $\sqrt{\mathrm{n}} \mathrm{u}$ follows the non-central $\mathrm{t}$ distribution with $\mathrm{n}-1$ degrees of freedom and noncentrality parameter $\delta$. A lower $100 \gamma \%$ confidence limit for $\mathrm{u}$ is obtained by $\operatorname{solving} \mathbf{p t}(\sqrt{\mathrm{n}} \mathrm{u}, \mathrm{n}-1, \mathrm{dl})$ $=\gamma$ for the noncentrality parameter $\mathrm{dl}$ where $\mathbf{p t}$ is the distribution function for the noncentral $\mathrm{t}$ distribution. The value of $\mathrm{ul}=\mathrm{d} 1 / \sqrt{\mathrm{n}}$ is the $\mathrm{LCL}$ for $\mathrm{u}$ and the $100 \gamma \% \mathrm{UCL}$ for $\mathrm{F}_{\mathrm{L}}$ is $\mathrm{Uf}\left(\mathrm{L}_{\mathrm{p}}, \gamma\right)=1-\mathrm{N}(\mathrm{ul})$, i.e. we are $100 \gamma \%$ confident that at most $\mathrm{Uf}\left(\mathrm{L}_{\mathrm{p}}, \gamma\right)$ percent of the Xs are greater than $\mathrm{L}_{\mathrm{p}}$. The $100 \gamma \%$ lower confidence limit $\operatorname{Lf}\left(\mathrm{L}_{\mathrm{p}}, \gamma\right)$ is obtained in a similar way. The $\mathrm{R}$ function efcl $(\mathbf{x}, \gamma, \mathrm{L}, \mathrm{T})$ returns lognormalbased point and $100 \gamma \%$ lower and upper confidence limits for the exceedance fraction $\mathrm{F}_{\mathrm{L}}$ (expressed as a percent ) for complete samples (see the Appendix).

The relationship between the upper tolerance limit and the exceedance fraction is summarized as follows:

$$
\begin{array}{ll}
\mathrm{H}_{0}: \mathrm{X}_{\mathrm{p}} \geq \mathrm{L}_{\mathrm{p}} & \text { reject } \mathrm{H}_{0} \text { if } \mathrm{UX}(\mathrm{p}, \gamma)<\mathrm{L}_{\mathrm{p}}, \\
\mathrm{H}_{0}: \mathrm{F}_{\mathrm{L}} \geq \mathrm{F}_{0}=1-\mathrm{p} & \text { reject } \mathrm{H}_{0} \text { if } \mathrm{Uf}\left(\mathrm{L}_{\mathrm{p}}, \gamma\right)<\mathrm{F}_{0} .
\end{array}
$$

If, for example, $\mathrm{p}=.95, \gamma=0.95$, and $\mathrm{L}_{\mathrm{p}}=0.2$ then $\mathrm{F}_{0}=.05(5 \%) . \mathrm{H}_{0}$ is rejected if $\mathrm{UX}(.95, .95) \leq 0.2$, or if Uf $(0.2,0.95) \leq 5 \%$, and the exposure profile is considered acceptable. Note that if the lower confidence limit $\operatorname{Lf}(\mathrm{L}, \gamma)>\mathrm{F}_{0}=1$-p this indicates that, with confidence level gamma, at least $\mathrm{Lf}(\mathrm{L}, \gamma) \%$ of the Xs exceed $L_{p}$. This is equivalent to finding that the lower confidence limit for $X_{p}$ is greater than $L_{p}$. Tuggle(1982) provides futher discussion of tolerance limits (and implicitly the exceedance fraction) as well as the choice of the values of $p, L_{p}$, and $\gamma$ that determine conditions for an acceptable level of exposure. It is of interest to note that confidence limits for $F$ require $L_{p}$ and $\gamma$ (not $p$ ), and confidence limits for $\mathrm{X}_{\mathrm{p}}$ require $\mathrm{p}$ and $\gamma\left(\right.$ not $\left.\mathrm{L}_{\mathrm{p}}\right)$. The Type I error for this procedure is $\leq \alpha=(1-\gamma)=$ probability of rejecting Ho when it is true; i.e., incorrectly deciding that the exposure is acceptable (e.g., workplace is safe). The Type II error, $\beta$, is the probability of failing to reject $\mathrm{H}_{0}$ when the alternative hypothesis, say $\mathrm{F}_{\mathrm{L}}=\mathrm{F}^{*}\left(<\mathrm{F}_{0}\right)$ is true, i.e. deciding that an acceptable exposure profile is not acceptable (clean object is contaminated.) The power $=(1-\beta)$ of this test is the probability of correctly deciding that an exposure profile is acceptable. The power depends on the sample size and the "true" value of the exceedance fraction when the alternative hypothesis is true. For complete samples from the lognormal distribution 
the power is $\mathbf{p t}\left(\mathrm{t}_{0}, \mathrm{n}-1, \lambda_{1}\right)$ where the non-centrality parameter is $\lambda_{1}=\mathrm{z}_{\mathrm{F}}{ }{ }_{\mathrm{n}}$, and $\mathrm{t}_{0}=\mathrm{t}^{\prime}\left(\mathrm{n}-1, \alpha, \lambda_{0}\right)$ is the $100 \alpha$ th percentile of the non-central $t$ distribution with $n-1$ degrees of freedom and non-centrality parameter $\lambda_{0}=z_{\mathrm{F}} \sqrt{ } \mathrm{n}$. The exact sample size required to provide power of at least (1- $\beta$ ) may be obtained (Lyles and Kupper,1996) by finding the smallest integer $\mathrm{n}$ such that

$$
\mathrm{t}^{\prime}\left(\mathrm{n}-1, \alpha, \lambda_{0}\right)-\mathrm{t}^{\prime}\left(\mathrm{n}-1,1-\beta, \lambda_{1}\right) \geq 0 .
$$

The R function fnlnf(fstar,pow,p,gam) in the Appendix is used to find $\mathrm{n}$.

\section{ANALYSIS OF DATA WITH NON-DETECTS}

In situations where an exposure measurement may be less than a detection limit exact methods have not been developed for the lognormal model. The maximum likelihood principle can be used for parameter estimation, and to obtain large sample equivalents of confidence limits for the mean exposure level, the 100 pth percentile, and the exceedance fraction. For a detailed discussion of assumptions, properties, and computational issues related to ML estimation see Cox and Hinkley (1979) and Cohen (1991).

\subsection{MAXIMUM LIKLIHOOD ESTIMATION FOR LOGNORMAL DATA WITH NON-DETECTS}

For notational convenience the $m$ detected values $x_{i}$ are listed first followed by the $x_{i}^{*}$ indicating non-detects, so that the data are $\mathbf{x}=\left\{\mathrm{x}_{\mathrm{i}}, \mathrm{i}=1, \ldots, \mathrm{m}, \mathrm{x}_{\mathrm{i}}^{*}, \mathrm{i}=\mathrm{m}+1, \ldots, \mathrm{n}\right\}$. If $\mathrm{x}_{\mathrm{i}}^{*}$ is the same for each non-detect, this is referred to as a left singly censored sample (Type I censoring) and $x^{*}$ is the DL. If the $\mathrm{X}_{\mathrm{i}}^{*}$ are different, this is known as randomly (or progressively) left censored data [Cohen (1991) and Schmoyer et al (1996)]. In some situations a value of 0 is recorded when the exposure measurement is less than the DL. In this situation, the value of $\mathrm{x}_{\mathrm{i}}^{*}$ is the DL indicating that $\mathrm{x}_{\mathrm{i}}$ is in the interval $\left(0, \mathrm{x}_{\mathrm{i}}^{*}\right)$. The probability density function for lognormal distribution is

$$
\mathrm{g}(\mathrm{x} ; \mu, \sigma)=\exp \left[-1 / 2(\log (\mathrm{x})-\mu)^{2} / \sigma^{2}\right](\sqrt{2 \pi} \sigma \mathrm{x})^{-1}
$$

where $\mathrm{y}=\log (\mathrm{x})$ is normally distributed with mean $\mu$ and standard deviation $\sigma$ (Aitchison and Brown, 1969). The geometric mean of $\mathrm{X}$ is $\mathrm{GM}=\exp (\mu)$ and the geometric standard deviation is $\mathrm{GSD}=\exp (\sigma)$ [Strom and Stansbury(2000)] for a summary of these and other relationships for lognormal parameters. Assuming the data are a random sample from a lognormal distribution, the log of the likelihood function for the unknown parameters $\mu$ and $\sigma$ given the data is

$$
\mathrm{L}(\mu, \sigma)=\sum_{\mathrm{i}=1}^{\mathrm{m}} \log \left[\mathrm{g}\left(\mathrm{x}_{\mathrm{i}} ; \mu, \sigma\right)\right]+\sum_{\mathrm{i}=\mathrm{m}+1}^{\mathrm{n}} \log \left[\mathrm{G}\left(\mathrm{x}_{\mathrm{i}}^{*} ; \mu, \sigma\right)\right],
$$

where $\mathrm{G}\left(\mathrm{x}^{*} ; \mu, \sigma\right)$ is the lognormal distribution function, i.e. $\mathrm{G}\left(\mathrm{x}^{*} ; \mu, \sigma\right)$ is the probability that $\mathrm{x}$ is less than or equal to $x^{*}$. The ML equations are obtained by differentiating the log-likelihood function (4) with respect to the $\mu$ and $\sigma$ and setting the result equal to 0 ; i.e., $\partial \mathrm{L}(\mu, \sigma) / \partial \mu=0, \partial \mathrm{L}(\mu, \sigma) / \partial \sigma=0$. These equations cannot be solved directly so a Newton-Raphson-type iterative algorithm is often used to find a root of the system of equations. This leads to

$$
\mathrm{C}\left(\theta^{0}\right) \delta^{0}=\mathrm{G}\left(\theta^{0}\right)
$$

where $\mathrm{G}(\theta)=\left[\partial \mathrm{L}(\theta) / \partial \theta_{\mathrm{j}}\right], \theta_{1}=\mu$ and $\theta_{2}=\sigma$, and $\mathrm{C}\left(\theta^{0}\right)$ is the $2 \times 2$ information matrix with elements $\mathrm{c}_{\mathrm{jk}}=$ $\partial^{2} \mathrm{~L}(\theta) / \partial \theta_{\mathrm{j}} \partial \theta_{\mathrm{k}}, \mathrm{j}, \mathrm{k}=1,2$. Each of the elements in $\mathrm{C}$ and $\mathrm{G}$ is elevated at the value of an initial estimate 
$\theta^{0}=\left(\mu^{0}, \sigma^{0}\right)$. This linear system of equations (5) is solved for $\delta^{0}$, and the new value $\theta^{1}=\theta^{0}+\delta^{0}$ is obtained. The procedure is repeated until a stable solution $\hat{\boldsymbol{\theta}}$ is reached; i.e., $\mathrm{G}(\hat{\boldsymbol{\theta}})=0$ and $\mathrm{C}(\hat{\boldsymbol{\theta}})$ is negative definite. The large sample covariance matrix of the ML estimate $\hat{\boldsymbol{\theta}}$ is obtained by inverting the information matrix evaluated at $\hat{\boldsymbol{\theta}}$, i.e. $\mathrm{V}(\hat{\boldsymbol{\theta}})=\mathrm{C}(\hat{\boldsymbol{\theta}})^{-1}$. The numerical approach used here is based on the R function optim, a general-purpose optimization procedure that includes the Nelder-Mead, quasiNewton, and conjugate-gradient algorithms. If the algorithm converges (as indicated by the convergence code from optim) and $\hat{\boldsymbol{\theta}}$ is an interior point in the parameter space, it is the unique global maximum of (4) for the situation considered here. The ML estimates $\hat{\mu}, \hat{\sigma}$, and standard errors are obtained using the $\mathrm{R}$ function mIndln provided in the Appendix. Note that for complete samples $\mathrm{m}=\mathrm{n}$ and the second term in equation (1) is not present. In this case, the solution of the likelihood equations result in well known estimate $\hat{\mu}=\Sigma \mathrm{y}_{\mathrm{i}} / \mathrm{n}, \hat{\sigma}=\left[\Sigma\left(\mathrm{y}_{\mathrm{i}}-\hat{\mu}_{\mathrm{i}}\right)^{2} / \mathrm{n}\right]^{1 / 2}$, where $\mathrm{y}_{\mathrm{i}}=\log \left(\mathrm{x}_{\mathrm{i}}\right)$.

\subsection{CONFIDENCE LIMITS FOR THE MEAN EXPOSURE LEVEL WITH NON-DETECTS}

To test the hypothesis $\mathrm{H}_{0}: \mu_{\mathrm{x}} \geq \mu_{\mathrm{x}}^{*}$, at the $\alpha=1-\gamma$ significance level a one-sided upper $100 \gamma \%$ confidence limit is needed. The first method considered is to use the censored data equivalent of Cox's direct method; i.e., calculate $\hat{\varphi}=\hat{\mu}+1 / 2 \hat{\sigma}^{2}$, $\operatorname{var}(\hat{\varphi})=\operatorname{var}\left(\hat{\mu}+1 / 2 \hat{\sigma}^{2}\right)$ where

$$
\operatorname{var}(\hat{\varphi})=\operatorname{var}(\hat{\mu})+1 / 4 \operatorname{var}\left(\hat{\sigma}^{2}\right)+\operatorname{cov}\left(\hat{\mu}, \hat{\sigma}^{2}\right) \text {. }
$$

In (6) $\hat{\mu}$ and $\hat{\sigma}^{2}$ are the ML estimates of $\mu$ and $\sigma^{2}$, and the estimated variances and covariance are obtained from

$$
\mathrm{V}(\hat{\boldsymbol{\theta}})=\left[\begin{array}{lc}
\operatorname{var}(\hat{\mu}) & \operatorname{cov}\left(\hat{\mu}, \hat{\sigma}^{2}\right) \\
\operatorname{cov}\left(\hat{\mu}, \hat{\sigma}^{2}\right) & \operatorname{var}\left(\hat{\sigma}^{2}\right)
\end{array}\right] .
$$

The ML estimate of $\mu_{\mathrm{x}}$ is $\exp (\hat{\varphi})$, the $100 \gamma \% \mathrm{LCL}$ for $\mu_{\mathrm{x}}$ is $\exp [\hat{\varphi}-\mathrm{t} \operatorname{var}(\hat{\varphi})]$, and the $100 \gamma \% \mathrm{UCL}$ for $\mu_{\mathrm{x}}$ is $\exp [\hat{\varphi}+\mathrm{t} \operatorname{var}(\hat{\varphi})]$, where $\mathrm{t}=\mathrm{t}(\gamma, \mathrm{m}-1)$. The resulting confidence interval (LCL,UCL) has confidence level $100(2 \gamma-1) \%$. An equivalent procedure is to estimate $\varphi=\mu+1 / 2 \sigma^{2}$ and its standard error directly, i.e. by solving (5) with $\theta_{1}=\mu+1 / 2 \sigma^{2}$ and $\theta_{2}=\sigma^{2}$. The R function mlndln provided in the Appendix returns ML estimates of $\mu, \sigma, \varphi, \sigma^{2}$, and estimates of the standard errors for each of the parameter.

A second method for obtaining an UCL for $\mu_{\mathrm{x}}$ is based on the procedure proposed by Lyles and Kupper (1996) for the complete data case. They use the relationship between the statistics $\bar{y}+\mathrm{cs}_{\mathrm{y}}$ and the noncentral $t$ distribution to obtain an approximate UCL for $\log \left(\mu_{\mathrm{x}}\right)$ of $\overline{\mathrm{y}}+\hat{\mathrm{c}}_{\mathrm{u}} \mathrm{s}_{\mathrm{y}}$ where,

$$
\hat{\mathrm{c}}_{\mathrm{u}}=[-\hat{\delta} \sqrt{\mathrm{n} /(\mathrm{n}-1)}] / \chi(\alpha, \mathrm{n}-1)+\mathrm{t}(1-\alpha, \mathrm{n}-1) / \sqrt{\mathrm{n}} \text {. }
$$

In (8), $\chi(\alpha, n-1)$ is the positive square root of the $100 \alpha$ percentile of the chi-square distribution with $n-1$ degrees of freedom, and $\hat{\delta}=-\sqrt{n} \mathrm{~s}_{y} / 2$. The quantity $\hat{\mathrm{c}}_{\mathrm{u}}$ is an estimate of the upper bound of $\mathrm{c}=-\mathrm{t}^{\prime}(\mathrm{n}-1, \alpha, \delta) / \sqrt{\mathrm{n}}$ where $\mathrm{t}^{\prime}$ is the $100 \alpha$ th percentile of the noncentral $\mathrm{t}$ distribution with $\mathrm{n}-1$ degrees of freedom and non centrality parameter $\delta=-\sqrt{n} \sigma / 2$. For censored data, an approximate $\log (\mathrm{UCL})$ for $\mu_{\mathrm{x}}$ is $\hat{\mu}+\hat{\mathrm{c}}_{\mathrm{u}} \hat{\sigma}$ where in calculating $\hat{\mathrm{c}}_{\mathrm{u}} \mathrm{n}$ is replaced with $\mathrm{m}$. The $\log (\mathrm{LCL})$ is obtained in 
a similar way. We speculate that the $100 \gamma \%$ approximate UCL for $\mu_{x}, \exp \left(\hat{\mu}+\hat{c}_{u} \hat{\sigma}\right)$ should be a conservative upper bound. When there are no non-detects (i.e. $m=n)$ Lyles and Kupper (1996) have shown that this procedure is similar in terms of power and Type I error rate to Land's exact method in most situations they considered. Recall that the exact method depends on $\hat{\mu}$ and $s_{y}^{2}$ being independent and respectively normally and a constant times a chi-square. For left censored data the $\operatorname{cov}\left(\hat{\mu}, \hat{\sigma}^{2}\right)$ (see equation 6) is negative and increases in magnitude as the proportion of non-detects increases. The $\mathrm{R}$ function $\mathrm{LKcl}$ computes confidence limits for $\mu_{\mathrm{x}}$ using this approximate method.

\subsection{CONFIDENCE LIMITS FOR THE PTH PERCENTILE WITH NON-DETECTS}

The point estimate of $y_{p}=\log \left(X_{p}\right)$ is $\hat{y}_{p}=\hat{\mu}+z_{p} \hat{\sigma}$ with variance

$$
\operatorname{var}\left(\hat{\mathrm{y}}_{\mathrm{p}}\right)=\operatorname{var}\left(\hat{\mu}+\mathrm{z}_{\mathrm{p}} \hat{\sigma}\right)=\operatorname{var}(\hat{\mu})+\mathrm{z}_{p}^{2} \operatorname{var}(\hat{\sigma})+2 \mathrm{z}_{\mathrm{p}} \operatorname{cov}(\hat{\mu}, \hat{\sigma})
$$

The $100 \gamma \%$ LCL and UCL for $\mathrm{X}_{\mathrm{p}}$ are

$$
\begin{aligned}
& \mathrm{LX}(\mathrm{p}, \gamma)=\exp \left[\hat{\mathrm{y}}_{\mathrm{p}}-\mathrm{t}(\gamma,(\mathrm{m}-1)) \operatorname{var}\left(\mathrm{y}_{\mathrm{p}}\right)^{1 / 2}\right] \\
& \mathrm{UX}(\mathrm{p}, \gamma)=\exp \left[\hat{\mathrm{y}}_{\mathrm{p}}+\mathrm{t}(\gamma,(\mathrm{m}-1)) \operatorname{var}\left(\mathrm{y}_{\mathrm{p}}\right)^{1 / 2}\right] .
\end{aligned}
$$

$\mathrm{UX}(\mathrm{p}, \gamma)$ is the estimated $100 \mathrm{p}-100 \gamma$ geometric upper tolerance limit. The ML estimates of $\operatorname{var}(\hat{\mu})$, $\operatorname{var}(\hat{\sigma})$, and $\operatorname{cov}(\hat{\mu}, \hat{\sigma})$ are obtained from the ML variance-covariance matrix using $\mathrm{R}$ function mIndln provided in the Appendix. The null hypothesis $\mathrm{H}_{0}: \mathrm{X}_{\mathrm{p}} \geq \mathrm{L}_{\mathrm{p}}$ is rejected at the $\alpha=(1-\gamma)$ significance level if $100 \gamma \% \mathrm{UCL}$ for $\mathrm{X}_{\mathrm{p}}$ is less than $\mathrm{L}_{\mathrm{p}}$ (indicating the exposure profile is acceptable). A second method that can be used to estimate the upper tolerance limit is to treat $\hat{\mu}$ and $\hat{\sigma}$ as if they were obtained from a complete sample of size $m$ and calculate $U X(p, \gamma)=\exp (\hat{\mu}+K \hat{\sigma})$, where $K$ is obtained from the noncentral $\mathrm{t}$ distribution using $\mathrm{m}, \mathrm{p}$, and $\gamma$ as described in Section 2.2. If there are no non-detects, then $\mathrm{m}=\mathrm{n}$ and method 2 provides the exact upper tolerance limit ( provided the unbiased estimate of $\sigma^{2}$ is used). The R function Inclxpnd at the AEOD web site calculates estimates of LX $(p, \gamma)$ and UX(p, $\gamma)$ using both large sample ML approach (method 1) and using approximate K values (method 2). Method 2 is the result of "analogical reasoning" and it appears to be a conservative upper bound for UX(p, $\gamma)$ for

lognormal data with non-detects. The $\mathrm{K}$ factor in Section 2.2 is obtained using the fact that $\overline{\mathrm{y}}$ and $\mathrm{s}_{\mathrm{y}}^{2}$ are independent statistics calculated from a random sample from a normal distribution Johnson and Welch (1940). The ML estimates of $\mu$ and $\sigma^{2}$ from censored samples do not satisfy these assumptions.

\subsection{CONFIDENCE LIMITS FOR EXCEEDANCE FRACTION WITH NON-DETECTS}

The ML point estimate of $F_{L}$ is $f=1-N(v)$ where $v=[\log (L)-\hat{\mu}] / \hat{\sigma}$. The large sample $100 \gamma \%$ LCL for $\mathrm{V}=[\log (\mathrm{L})-\mu] / \sigma$ is $\mathrm{LCLv}=\mathrm{v}-\mathrm{t}(\gamma, \mathrm{m}-1) \operatorname{var}(\mathrm{v})^{1 / 2}$, where

$$
\operatorname{var}(\mathrm{v})=\mathrm{p}_{1}^{2} \operatorname{var}(\hat{\mu})+\mathrm{p}_{2}^{2} \operatorname{var}(\hat{\sigma})+2 \mathrm{p}_{1} \mathrm{p}_{2} \operatorname{cov}(\hat{\mu}, \hat{\sigma}),
$$

with $p_{1}=\partial v / \partial \mu=-1 / \hat{\sigma}$ and $p_{2}=\partial v / \partial \sigma=-[\log (L)-\hat{\mu}] / \hat{\sigma}^{2}$. The $100 \gamma \% \operatorname{UCL}$ for $F_{L}$ is $\operatorname{Uf}(\mathrm{L}, \gamma)=1-$ $\mathrm{N}(\mathrm{LCLv})$. 
The $100 \gamma \% \mathrm{LCL}$ for $\mathrm{F}_{\mathrm{L}}$ is $\mathrm{LF}(\mathrm{L}, \gamma)=1-\mathrm{N}(\mathrm{UCLv})$, where $\mathrm{UCLv}=\mathrm{u}+\mathrm{t}(\gamma, \mathrm{m}-1) \operatorname{var}(\mathrm{v})^{1 / 2}$. The null hypothesis $\mathrm{H}_{0}: \mathrm{F}_{\mathrm{L}}=1-\mathrm{p}$ is rejected if the $100 \gamma \% \mathrm{UCL}$ for $\mathrm{F}_{\mathrm{L}}$ is less than $\mathrm{F}_{0}$, indicating that the exposure profile is acceptable. The large sample ML estimates of the exceedance fraction and $100 \gamma \%$ confidence limits for lognormal data with non-detects are obtained using the $\mathrm{R}$ function efclnd in the Appendix.

A second method that can be used to estimate the exceedance fraction and $100 \gamma \%$ confidence limits is to treat $\hat{\mu}$ and $\hat{\sigma}$ as if they were obtained from a complete sample of size $m$ and use the complete sample method described in Section 2.3. Method 2 is the result of "analogical reasoning" and it appears to be a conservative upper bound for $\mathrm{Uf}(\mathrm{L}, \gamma)$ for lognormal data with non-detects. The R function efcl2 in the Appendix is used to calculate these limits.

\subsection{NON-PARAMETRIC METHODS FOR SAMPLES WITH NON-DETECTS}

The product limit estimator (PLE) of the cumulative distribution function was first proposed by Kaplan and Meier (1958) for right censored data. Turnbull (1976) provides a more general treatment of nonparametic estimation of the distribution function for arbitrary censoring. For randomly left censored data, the PLE is defined as follows [Schmoyer et al. (1996)]. Let $a_{1}<\ldots<a_{M}$ be the M distinct values at which detects occur, $r_{j}$ is the number of detects at $a_{j}$, and $n_{j}$ is the sum of non-detects and detects that are less than or equal to $a_{j}$. Then the PLE is defined to be 0 for $0 \leq x \leq a^{0}$, where $a^{o}$ is $a_{1}$ or the value of the detection limit for the smallest non-detect if it is less than $a_{1}$. For $a^{o} \leq x<a_{M}$ the PLE is $\hat{F}_{j}=\prod_{j}\left(n_{j}\right.$ $\left.r_{j}\right) / n_{j}$, where the product is over all $a_{j}>x$, and the PLE is 1 for $x \geq a_{M}$. When there are only detects this reduces to the usual definition of the empirical cumulative distribution function. The $\mathrm{R}$ function plend at the AEOD web site is used to compute the PLE.

The PLE is used to determine the plotting positions on the horizontal axis for the censored data version of a theoretical quantile-quantile (q-q) plot for the lognormal distribution (see Chambers et al., 1983). Waller and Turnbull (1992) provide a good overview of q-q plots and other graphical methods for censored data. The lognormal q-q plot is obtained by plotting $a_{j}\left(\right.$ on $\log$ scale) versus $H_{j}=G^{-1}\left(\hat{P}_{j}\right)$, where

$G^{-1}$ is the inverse of the distribution function of the standard normal distribution and $\hat{P}_{j}=\left(\hat{F}_{j}+\hat{F}_{j-1}\right) / 2$ is the plotting position for $\mathrm{a}_{\mathrm{j}}$ [Meeker and Escobar (1998, Chap 6)]. Helsel and Cohen (1988) consider alternative procedures that can be used for calculating plotting positions for left censored data. In the complete data case without ties $\hat{\mathrm{P}}_{\mathrm{j}}=(\mathrm{j}-1 / 2) / \mathrm{n}$. If the lognormal distribution is a close approximation to the empirical distribution, the points on the plot will fall near a straight line. An objective evaluation of this is obtained by calculating the square of the correlation coefficient associated with the plot; i.e., $\mathrm{R}^{2}=\operatorname{cor}\left(\log a_{\mathrm{j}}, \mathrm{H}_{\mathrm{j}}\right)^{2}$. In the complete data case this will be a close approximation to the Shapiro-Wilk W statistic that is used as a test for normality. Verril and Johnson (1988) considers the large sample distribution of the correlation statistic for Type I and Type II right censored data. A formal test for normality of randomly left censored data has not been developed.

The mean $\left(\bar{x}_{p}\right)$ of the PLE is a censoring-adjusted point estimate of $\mu_{\mathrm{x}}$. An approximate standard error of the PLE mean can be obtained using the method of Kaplan and Meier (1958) and the $100 \gamma \%$ UCL is $\bar{x}_{p}+t(\alpha, m-1) s_{p}$, where $s_{p}$ is the Kaplan-Meier standard error of $\bar{x}_{p}$ adjusted by the factor $m /(m-1)$, where $\mathrm{m}$ is the number of detects in the sample. When there is no censoring this reduces to the second 
approximate method described by Land (1972). The R function kmms at the AEOD web site is used to calculate $\overline{\mathrm{x}}_{\mathrm{p}}, \mathrm{s}_{\mathrm{p}}$, and the confidence limits.

\subsection{NON-PARAMETRIC UPPER TOLERANCE LIMIT AND EXCEEDANCE FRACTION}

A non-parametric upper tolerance limit can be obtained using the method described by Somerville (1958). Given a random sample of size $\mathrm{n}$ from a continuous distribution, then, with a confidence level of at least $\gamma, 100$ p percent of the population will be below the $\mathrm{k}^{\text {th }}$ largest value in the sample. The maximum nondetect must be less than the $\mathrm{k}^{\text {th }}$ largest value. The value of $\mathrm{k}$ for specific values of $\mathrm{n}, \mathrm{p}$, and $\gamma$ can be obtained from published tables or, for any reasonable values of $\mathrm{n}, \mathrm{p}$, and $\gamma$, by using the $\mathrm{R}$ function nptl provided in the Appendix. The $100 \gamma \%$ upper tolerance bound is equivalent to an upper $100 \gamma \%$ confidence limit for the 100pth percentile of the population.

When the distribution function for the Xs is not specified a "nonparametric" approach can be used to estimate $F_{L}$ the proportion of measurements that exceed the limit L. Given a random sample of size $n$ the number $y$ of nonconforming observations (i.e., $y=$ number of $x_{i}>L$ ) is described using the binomial distribution. The point estimate of $F_{L}$ is $f=y / n$ and confidence limits are obtained using the method of Clopper and Pearson (1934) [Hahn and Meeker (1991, chap 6)] and the R documentation for base R function binom.test. The $\mathrm{R}$ driver function efclnp returns the point estimate of $F_{L}$ and the lower and upper $100 \%$ confidence limits for $\mathrm{F}_{\mathrm{L}}$.

\section{APPLICATIONS}

In several situations of practical interest statistical analysis of left censored data from a lognormal distribution are required. The "exact" results for complete samples described in Section 2 have not been developed for censored data. The methods presented here are "large sample" results and follow directly from the properties of ML estimators described in Section 3. Each of the examples will describe the censored data equivalent of the exact methods used with complete samples. The emphasis here is on describing the methods and software. The focus in the examples is two areas of application that are part of the Department of Energy (DOE) Chronic Beryllium Disease Prevention Program. The DOE is concerned with monitoring objects (e.g., equipment, buildings) for beryllium contamination and workers for exposure to beryllium in the workplace. The first example describes the results of a survey to evaluate possible beryllium "contamination" based on surface wipe sampling of a smelter facility used to recycle metal. The second example describes the results of a beryllium worker-monitoring program using 8-hour TWA. In both situations "limit values" have been established to determine if exposure levels are acceptable; i.e., the object is "clean" or the workplace is "safe." In general, the limit value will depend on the strategy that is being used as described in the introduction. In the examples the null hypothesis of interest is that the $95^{\text {th }}$ percentile of exposure distribution does not exceed the specified limit. Hewett (1996) explains that occupational exposure limits (OELs) are generally single shift limits used for day-today risk management that will also constrain long-term, working lifetime exposures of each individual worker to protective levels. OELs are based on health or toxicology studies that establish protective mean exposure levels. A work environment that rarely exceeds the OEL will also maintain mean levels well below the OEL. Day-to-day exposure prevention is achieved through investigations to determine cause and corrective actions for exposure measurements above the OEL.

Ninety-five-percent confidence that fewer than 5\% of measurements are above a specified limit is a statistical definition of compliance that has come into widespread use to determine the monitoring efforts needed to demonstrate compliance [see chapter 7, Mulhausen and Damiano (1998)]. In this situation the upper tolerance limit (i.e., the $95 \%$ UCL for the $95^{\text {th }}$ percentile) and the UCL for the exceedance fraction 
are of primary interest (see Section 2.3) to determine if the exposure distribution is acceptable. The exact results for samples from a lognormal (or normal) distribution described in Section 2 and the Appendices of Mulhausen and Damiano(1998) are based on the assumption of complete samples; i.e., no left censored data. The statistical methods and computer software for the analysis of left censored data described in Section 3 can be used to calculate the censored data equivalent of all of the statistics described by Mulhausen and Damiano (1998). Details describing R and the R driver functions used to obtain these results are described in the Appendix and at the AOED website. All of the R functions can be downloaded from the AOED web site.

In the examples, results obtained using $\mathrm{R}$ interactively are shown in a monospaced font $1 \mathrm{ike}$ this (where ">" is the R prompt). To duplicate these results in the examples read the Appendix and then visit the AOED web site and complete steps 1-4. Note that Exhibit 1 is listed at the end of readall.R at the AOED web site, and the data frame SESdata and character string IpSESdata will be in the R working directory.

\subsection{EXAMPLE 1. SURFACE WIPE SAMPLES FROM ELEVATED SEMELTER SURFACES}

The data in Exhibit 1 are 31 surface wipe samples from elevated surfaces of a smelter with beryllium contamination. Exhibit 1 illustrates one method that can be used to enter data into $\mathrm{R}$ in the format required for the ML estimation. This would normally be done by using a text editor to create a file (example1.txt). All characters on a line to the right of the \# sign are comments. The data is entered into the $\mathrm{R}$ working directory using the $\mathrm{R}$ function source; i.e, if the file is in the directory(folder) where the $\mathrm{R}$ session was initiated, source ("example1.txt") will input the vectors $\mathrm{x}$, det, and the data.frame SESdata.

Exhibit 1 of Section 4.1

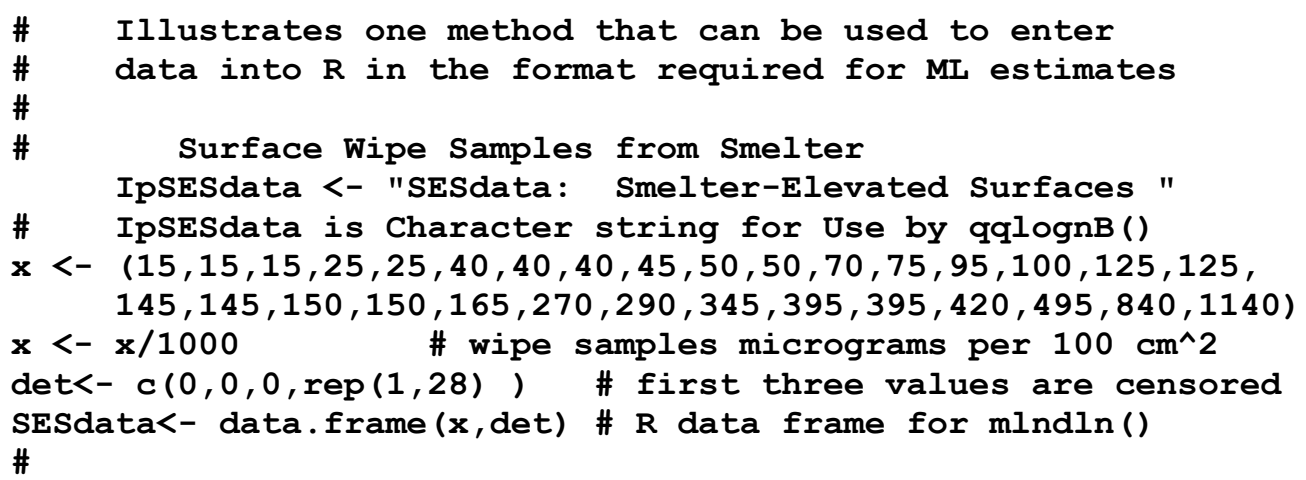

ML estimates of $\mu, \sigma, \log \left(\mu_{\mathrm{x}}\right)$, and $\sigma^{2}$ are obtained using :

$>\operatorname{mlnd} \ln ($ SESdata)

$\begin{array}{lrrrrrr} & \text { mu } & \text { sigma } & \text { logE } & \text { sig2 } & -2 \text { Log }(L) & \text { Conver } \\ \text { mle } & -2.2907643 & 1.2760000 & -1.4766777 & 1.6281796 & -12.852885390 & 0 \\ \text { sem1e } & 0.2311395 & 0.1754489 & 0.3137301 & 0.4477474 & -0.002005525 & 28\end{array}$

The $\mathrm{R}$ function mIndln is described in the Appendix and is available at the AOED website. The data in Exhibit 1 are shown graphically in Fiqure 1. ML estimates of $\mu$, and $\sigma$ are shown in title of the plot. To obtain Figure 1, use the following at the R prompt:

$>q q \operatorname{lognB}\left(\right.$ SESdata, IpSESdata, $L=0.2$, unit $=$ "mug/100 $\mathrm{cm}^{\wedge} 2 ", p=0.95$, gam=0.95)

If equipment is being evaluated for release to the public or for non beryllium use the DOE has established a release limit for removable beryllium contamination of $\mathrm{L}_{95}=0.2 \mu \mathrm{g} / 100 \mathrm{~cm}^{2}$. The ML estimate of the 


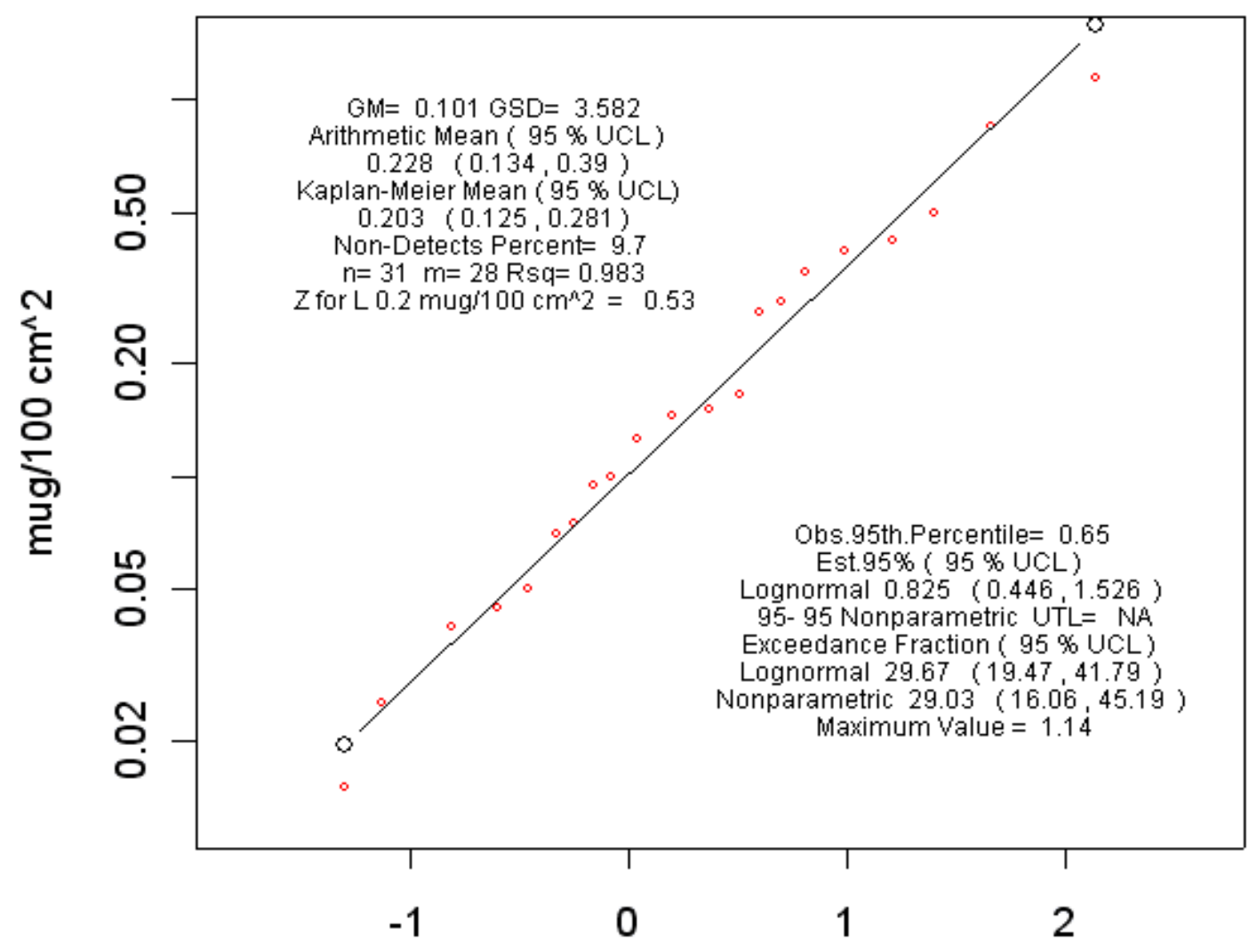

Normal Quantile

Figure 1. Results for Surface Wipe Samples in Example 1.

exceedance fraction (see Section 2.3), 95\% LCL, and 95\% UCL are obtained using R function efclnd based on the method described in Section 3.4;

$>$ efclnd (SESdata, gam $=0.95, L=0.2)$

$f \_M L E$ LCL_0.95 UCL_0.95

$29.6686419 .45963 \quad 41.80762$

The nonparametric estimates of the exceedance fraction, 95\% LCL, and 95\% UCL are obtained using efclnp based on the method described in Section 3.5:

$>$ efclnp(SESdata, gam $=0.95, L=0.2)$

$$
\text { fnp LCL_95 UCL_95 }
$$

29.0322616 .0611145 .19044 . 
The exceedance fraction is an estimate of the percentage of surface area that is expected to exceed the release limit $\mathrm{L}_{\mathrm{p}}=0.2 \mu \mathrm{g} / 100 \mathrm{~cm}^{2}$ with $\mathrm{p}=0.95$. Both the point estimate and the UCL for $\mathrm{F}$ exceed $\mathrm{F}^{\mathrm{O}}=100(1-\mathrm{p})=5 \%$, indicating that the equipment is not acceptable. In fact, the 95\% LCL indicates that at the $95 \%$ confidence level at least $19.5 \%$ of the surface area exceeds the release limit. These lognormal based and nonparametric estimates of the exceedance fraction and 95\% CLs are shown in the lower right of Figure 1 along with the lognormal based estimate of the $95^{\text {th }}$ percentile $\mathrm{X}_{\mathrm{p}}=0.825$, the lower $95 \% \mathrm{CL}$ $=\operatorname{LX}(0.95,0.95)=0.446$, and upper 95\% CL= UX $(0.95,0.95)=1.526$ (see Section 3.3). The GM, GSD, ML estimates of the (arithmetic) mean of X (with confidence limits) based on the lognormal model, the distribution free Kaplan-Meier mean (with confidence limits), the percent non-detects, the sample size (n), the number of detects $(m), R^{2}$ (as defined in Section 3.5), and the $\mathrm{z}$ value for the limit $\mathrm{L}_{\mathrm{p}}$ are in the upper left corner of Figure 1.

All of the these summary statistics and a brief description of each can be obtained using $\mathrm{R}$ function allss(dd,L,p,gam); e.g,

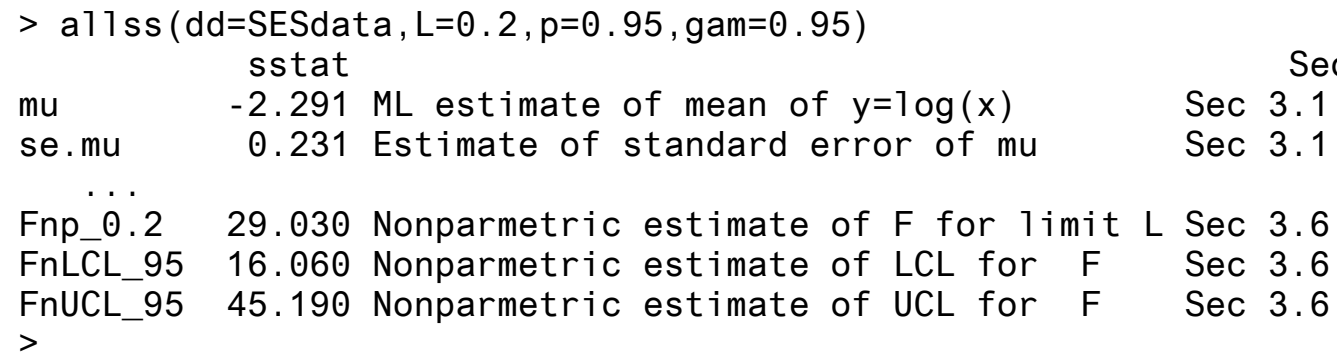

\subsection{EXAMPLE 2. TWA BERYLLIUM EXPOSURE DATA}

As part of a chronic disease prevention program the DOE adopted an 8-hour TWA OEL limit value of 0.2 micrograms per cubic meter proposed by the American Conference of Government Industrial Hygienists (DOE 10 CRF Part 850 and ACGIH 2004). Figure 2 summarizes the results of 280 personal 8-hour TWA beryllium exposure readings at a DOE facility. This data contains 175 non-detects that range in value from 0.005 to $0.100 \mu \mathrm{g} / \mathrm{m}^{3}$. This is an example of random (progressive) left censored data (available at the AOED web site in file beTWA.txt). The q-q plot in Figure 2 is based on the PLE as described in Section 3.5 and was calculated using the R function plend(beTWA). Figure 2 can be obtained using $\mathrm{R}$ utility function qqlognB. To obtain Figure 2, use the following at the R prompt:

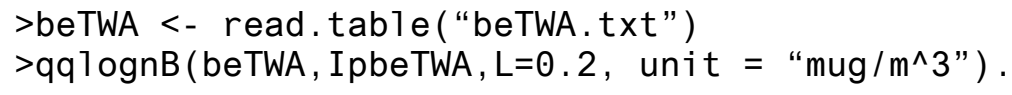

ML estimates of $\mu, \sigma, \log \left(\mu_{\mathrm{x}}\right)$, and $\sigma^{2}$ are obtained using :

The ML estimate of the 95-95 geometric upper tolerance limit is calculate using the results in Section 3.3 equation (9), i.e. $\hat{y}_{.95}=\hat{\mu}+z_{.95} \hat{\sigma}-2.652$ and 


$$
\begin{aligned}
\operatorname{var}\left(\hat{\mathrm{y}}_{\mathrm{p}}\right) & =\operatorname{Var}(\hat{\mu})+\mathrm{z}_{\mathrm{p}}^{2} \operatorname{var}(\hat{\sigma})+2 \mathrm{z}_{\mathrm{p}} \operatorname{cov}(\hat{\mu}, \hat{\sigma}) \\
& =0.1341^{2}+1.645^{2}(0.1155)^{2}+2 * 1.645(-.008918) \\
& =0.0247
\end{aligned}
$$

Then, using equation $6, \mathrm{UX}(0.95,0.95)=\exp \left[-2.652+1.659(0.0247)^{1 / 2}\right]=0.091$. The nonparametric upper tolerance limit from Section 3.6 is 0.13 . Both estimates are well below the limit $\mathrm{L}_{0.95}=0.2 \mu \mathrm{g} / \mathrm{m}^{3}$ indicating that the workplace acceptable (in compliance).

The lognormal based estimate of the exceedance fraction for $\mathrm{L}_{0.95}=0.2$ is $1.01 \%$, and the $95 \%$ upper confidence limit $\operatorname{Uf}(0.2,0.95)=3.24 \%<5 \%$ indicating the workplace is acceptable. The non-parametric estimate of the exceedance fraction is $1.43 \%$ with $95 \% \mathrm{UCL}=3.24 \%$. All of the above results provide strong support for the decision that the workplace is in compliance.

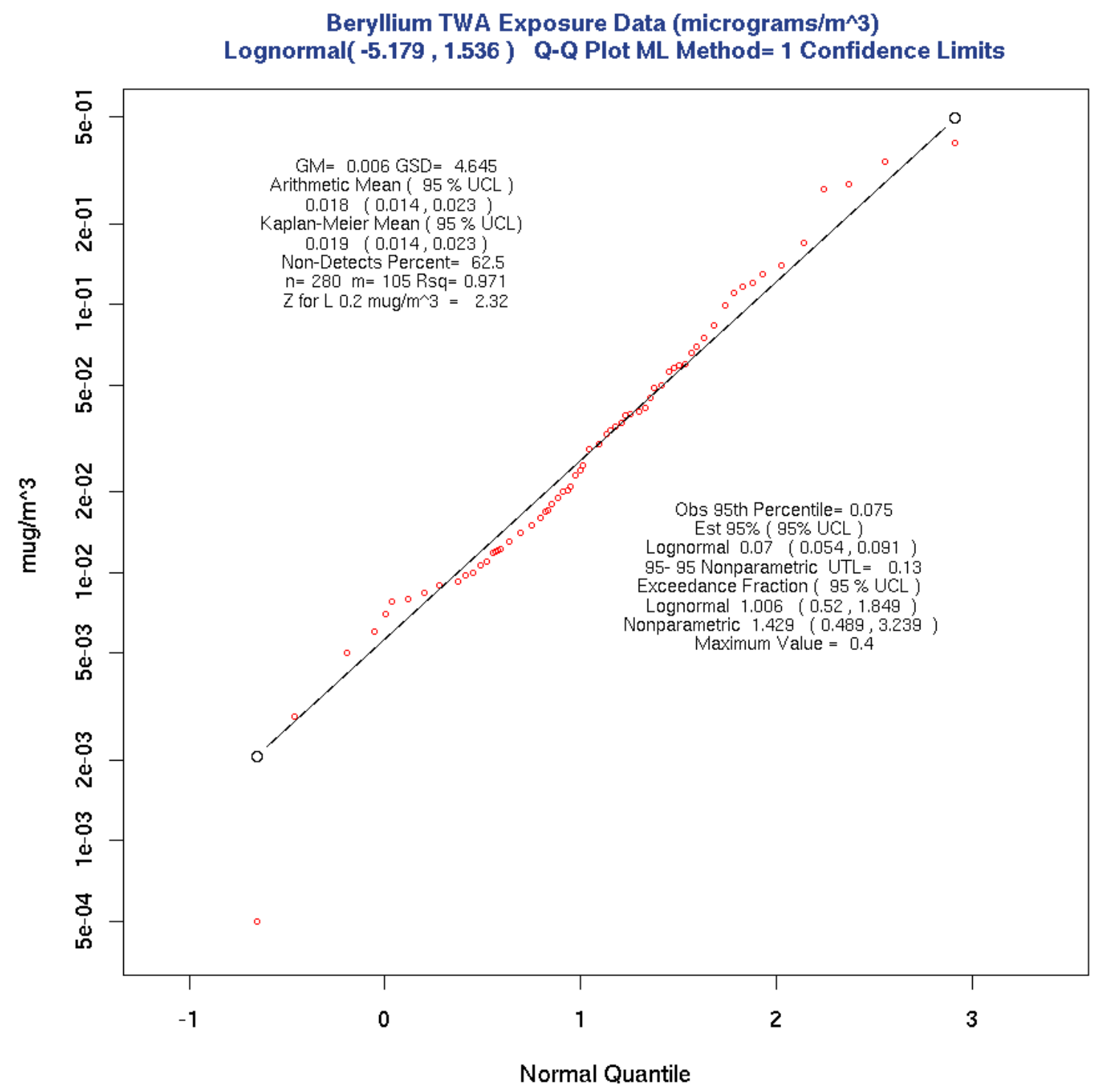

Figure 2. Results for 8-hour TWA Data in Example 2. 


\section{DISCUSSION}

After installing $\mathrm{R}$ software as described in the Appendix the $\mathrm{R}$ functions posted at the AOED web site can be used to analyze exposure data with non-detects. Data can be entered into R from text files that you create by copying data from word processing, spreadsheet or database files. The output txt files created by R can be imported back into files used for analysis, report writing and record keeping (see the AOED web site, Example 1, and the Appendix for more details). All of the statistics described in the AIHA Consensus Standard are calculated using the methods described in Sections 3 and 4 as illustrated in the examples. For all practical purposes there is no upper limit on the size of the data set that can be analyzed, and as long as there are at least two detected results most of the statistics will be calculated. The $\mathrm{R}^{2}$ statistic and lognormal q-q plots are equivalent to the $\mathrm{W}$ statistic and log probability plots described by Mulhausen and Damiano (1998), and are used in the same way to check on the lognormal assumption and select the appropriate metrics.

Note, however, that the results in Sections 3 and 4 are based on large-sample ML methods and the resulting confidence intervals may be "too short" in "small samples." Schmee et al. (1985) have considered confidence limits for the parameters $\mu$ and $\sigma$ for Type I right censored samples from the lognormal distribution. Their report indicates that "exact" results (obtained using Monte Carlo methods) are most useful when the number of uncensored observations is small. They found that when the number of uncensored observations is greater than 20 the agreement between exact and large sample ML confidence limits is good irrespective of the sample size. They did not consider confidence intervals for functions of $\mu$ and $\sigma$. As far as we know exact (small sample) results have not been developed for randomly (progressively) left censored data.

In this report the UCL for the $95^{\text {th }}$ percentile and the exceedance fraction (both functions of $\hat{\mu}$ and $\hat{\sigma}$ ) are of primary interest. In the complete data case the upper confidence limits $\mathrm{UX}(\mathrm{p}, \gamma)$ and $\mathrm{Uf}\left(\mathrm{L}_{\mathrm{p}}, \gamma\right)$ always yield equivalent results, i.e. the decision to reject $\mathrm{H}_{0}$ will always be the same. When the exposure measurements are subject to left censoring the exact methods cannot be used and this is no longer true. Table 1 presents the results from a simulation study that compares the censored ML estimates of UX(p, $\gamma)$ and $\operatorname{Uf}\left(\mathrm{L}_{\mathrm{p}}, \gamma\right)$ on the basis of power and type I error rates. The nominal values used were $\mathrm{p}=0.95, \gamma=$ 0.95 , power $=0.8, \mathrm{~L}_{\mathrm{p}}=1$, and detection limit $\mathrm{DL}=0.1$. The results in each cell in Table 1 are based on 2000 independently generated random samples from a lognormal distribution under $\mathrm{H}_{0}$ with $\mathrm{F}_{\mathrm{L}}=5 \%$, or separately under $\mathrm{H}_{1}$ with exceedance fraction $\mathrm{F}_{\mathrm{L}}=\mathrm{F}^{*}$ and sample size $\mathrm{n}^{*}$ (see columns 2 and 3 in Table I). Columns 3 through 13 in the table are the nominal values for the percent non-detects (PND) in each sample. The sample size was obtained using equation (2) with $\alpha=0.05,(1-\beta)=0.8$ and $\mathrm{F}^{*}=0.75 \%$, $1.5 \%$, and $3 \%$. Figure 3 provides a graphical summary of the relation between sample size and $\mathrm{F}^{*}$ for four levels of power. The three vertical line intersect the solid curve for power $=80 \%$ at $\mathrm{n}=34$ for $\mathrm{F}^{*}=$ $0.75 \%, 67$ for $\mathrm{F}^{*}=1.5 \%$, and 291 for $\mathrm{F}^{*}=3 \%$. For each of the 15 combination of values of $\mathrm{F}^{*}$ and PND the parameters of the lognormal distribution under $\mathrm{H}_{0}$ and $\mathrm{H}_{1}$ and were obtained by solving (with $\mathrm{L}_{\mathrm{p}}$ $=1$ and $\mathrm{DL}=0.1$ )

$$
\begin{aligned}
& \mu_{0}+\mathrm{z}_{\mathrm{p}} \sigma_{0}=\log \left(\mathrm{L}_{\mathrm{p}}\right) ; \mu_{0}+\mathrm{z}_{\mathrm{c}} \sigma_{0}=\log (\mathrm{DL}) \\
& \mu_{1}+\mathrm{z}_{1} \sigma_{1}=\log \left(\mathrm{L}_{\mathrm{p}}\right) ; \quad \mu_{1}+\mathrm{z}_{\mathrm{c}} \sigma_{1}=\log (\mathrm{DL}),
\end{aligned}
$$

With $z_{p}=1.645, z_{1}$ is based on the value of $F^{*}$, and $z_{c}$ is determined by the value of PND. For example, with $\mathrm{F}^{*}=1.5 \%$ and PND $=40 \% \mathrm{z}_{1}=2.17, \mathrm{z}_{\mathrm{c}}=-0.2533, \mu_{1}=-2.062, \sigma_{1}=-0.950, \mu_{0}=-1.995$, and $\sigma_{0}=$ 1.213. This approach requires that for a given value of $\mathrm{F}^{*}$ the percent non-detects will be the same under $\mathrm{H}_{0}$ and $\mathrm{H}_{1}$. The simulation study was done as follows: 
Table 1. Results of Simulation Study with Nominal Value $p=0.95$

Power $=80 \%, \alpha=5 \%, \mathrm{~L}_{\mathrm{p}}$, and $\mathrm{DL}=0.1$

Type I Error ${ }^{\mathrm{A}}$

Empirical Estimates
Power $^{\mathrm{B}}$

Empirical Estimates

\begin{tabular}{|c|c|c|c|c|c|c|c|c|c|c|c|c|}
\hline \multicolumn{6}{|c|}{$\mathrm{PND}^{\mathrm{I}}$} & \multicolumn{7}{|c|}{ PND } \\
\hline Procedure & $F^{* G}$ & $n^{\mathrm{H}}$ & 1 & 20 & 40 & 60 & 80 & 1 & 20 & 40 & 60 & 80 \\
\hline$U f^{c}$ & 0.75 & 34 & 6.5 & 5.2 & 4.5 & 3.9 & 1.1 & 82 & 76.1 & 68.5 & 55.5 & 24.9 \\
\hline Uf & 1.5 & 67 & 5.5 & 5 & 5 & 4.2 & 4 & 80.6 & 76.8 & 69.1 & 64.3 & 50.8 \\
\hline Uf & 3 & 291 & 5.8 & 4.5 & 5.1 & 5.3 & 4.8 & 82.2 & 79 & 72.8 & 67.5 & 64.8 \\
\hline$U X^{D}$ & 0.75 & 34 & 10.5 & 8.8 & 9.8 & 10.8 & 11.5 & 89.1 & 86.2 & 82.8 & 79.1 & 73 \\
\hline UX & 1.5 & 67 & 7.6 & 7 & 7.6 & 8.2 & 10.2 & 85.8 & 84.2 & 78.3 & 76.5 & 74.1 \\
\hline UX & 3 & 291 & 6.3 & 5.5 & 6.2 & 7 & 8 & 84.2 & 81.4 & 77 & 73.6 & 72.8 \\
\hline Method $2^{\mathrm{E}}$ & 0.75 & 34 & 5.4 & 38 & 21 & 0.8 & 01 & 79.1 & 698 & 523 & 301 & 68 \\
\hline Method 2 & 1.5 & 67 & 4.8 & 3.5 & 2.4 & 0.7 & 0.1 & 78.2 & 69.5 & 54.6 & 35.9 & 8.9 \\
\hline Method 2 & 3 & 291 & 5.1 & 3.5 & 2 & 1.1 & 0.2 & 80.7 & 73.8 & 59.8 & 40.2 & 11.1 \\
\hline Exact $^{F}$ & 0.75 & 34 & 5.5 & 4.8 & 5.2 & 5.4 & 4.7 & 79.8 & 81.3 & 79.9 & 80.5 & 81.2 \\
\hline Exact & 1.5 & 67 & 4.9 & 4.7 & 4.2 & 4.8 & 4.8 & 79 & 81 & 78.6 & 80 & 80.9 \\
\hline Exact & 3 & 291 & 5.1 & 4.7 & 4.7 & 5.4 & 4.9 & 81.2 & 81.8 & 80.2 & 79 & 79.8 \\
\hline
\end{tabular}

\footnotetext{
${ }^{A}$ The empirical type I error estimate is percent of 2000 tests rejected under $\mathrm{H}_{0}$

${ }^{\mathrm{B}}$ The empirical power estimate is percent of 2000 tests rejected under $\mathrm{H}_{1}$

${ }^{\mathrm{C}}$ The Uf procedure refers to results using Uf(1,0.95) ML method 1

${ }^{D}$ The XU procedure refers to results using UX $(0.95,0.95)$ ML method 1

${ }^{\mathrm{E}}$ Method 2 is based on analogical reasoning as describe in the methods section

${ }^{\mathrm{F}}$ The exact procedure refers to exact results from the uncensored samples

${ }^{\mathrm{G}} \mathrm{F}^{*}$ is the value of the exceedance fraction under $\mathrm{H}_{1}$

${ }^{\mathrm{H}} \mathrm{n}$ is sample size based on equation 2

${ }^{\mathrm{I}}$ PND refers to the nominal percent non-detects
} 


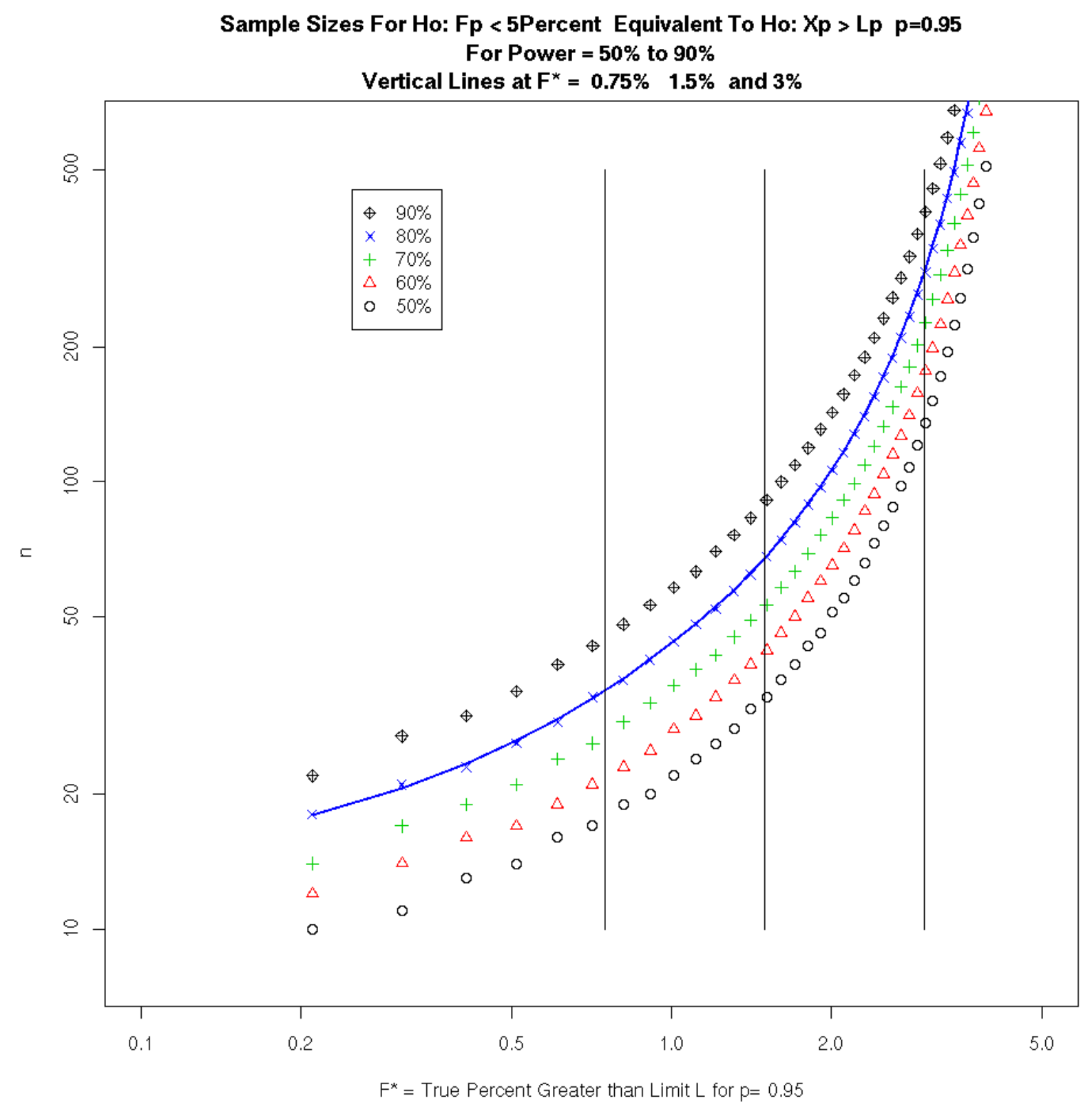

Figure 3. Sample Size Versus F* for Five Levels of Power 
For each value of $\mathrm{F}^{*}, \mathrm{n}^{*}$ and PND solve equation (11) for $\mu_{0}$ and $\sigma_{0}$; solve equation (12) for $\mu_{1}$ and $\sigma_{1}$

(1) Obtain a random sample of size $\mathrm{n}^{*}$ from a lognormal distribution with parameters $\mu_{0}$ and $\sigma_{0}$. For each complete sample calculate the value of $\bar{y}$ and $s_{\mathrm{y}}$. Replace each sample value $<\mathrm{DL}$ with DL and calculate the ML estimates $\hat{\mu}, \hat{\sigma}$, their standard errors, covariance, and $m$ using mIndln.

(2) Obtain a random sample of size $\mathrm{n}^{*}$ from a lognormal distribution with parameters $\mu_{1}$ and $\sigma_{1}$. For each complete sample calculate the value of $\bar{y}$ and $s_{y}$. Replace each sample value $<D L$ with DL and calculate the ML estimates $\hat{\mu}, \hat{\sigma}$, their standard errors, covariance, and $\mathrm{m}$ using mIndln.

(3) Save the results from 2 and 3 as a row in a data frame.

(4) Repeat steps 1-4 2000 times.

The results in columns 4 through 8 in Table I are empirical estimates of the Type I error rate (percent of 2000 samples rejecting $\mathrm{H}_{0}$ ) for the method in column 1 under $\mathrm{H}_{0}$ for the sample size in column 3 and PND at the top of the column. The results in columns 9 through 13 are the empirical power estimates, i.e. percent of 2000 tests that rejected $\mathrm{H}_{0}$ under $\mathrm{H}_{1}$ with true value $\mathrm{F}_{\mathrm{L}}=\mathrm{F}^{*}$ in column 2 and sample size in column 3. The first three rows demonstrate that using the UCL for the exceedance fraction $\mathrm{Uf}(\mathrm{p}, \gamma)$ results in a Type I error rate (columns 4 through 8 ) that is close to or below the nominal level of $5 \%$ for censoring levels above $20 \%$. The type I error rate decreases as the PND increase. Columns 9 through 13 of the first three rows show a decrease in power for $\operatorname{Uf}(\mathrm{p}, \gamma)$ as a result of increasing levels of censoring. The Type I error rate for upper tolerance limit $\mathrm{UX}(\mathrm{p}, \gamma)$ (see Table 1 rows 3-6 columns 4-8 ) clearly exceeds the nominal level for all situations considered, and consequently the higher levels of power are misleading. The results for method 2 are very conservative; i.e,. the UCLs for the exceedance fraction and $95^{\text {th }}$ percentile provide a conservative upper bound. The last three rows in Table I are based on the exact values of the test statistics, either $\operatorname{Uf}(\mathrm{p}, \gamma)$ or $\mathrm{UX}(\mathrm{p}, \gamma)$, that were computed from each sample before the sample was censored. These empirical rates are in close agreement with the nominal rates. The average value of the percent non-detect $(100 * \mathrm{~m} / \mathrm{n})$ was calculated for each of the 30 samples and was within $0.1 \%$ of the nominal value in every case. These results suggest that in situations where the exceedance fraction is of interest for lognormal data with non-detects the UCL for the exceedance fraction is preferred procedure. 


\section{ACKNOWLEDGEMENTS}

This work was supported in part by the Office of Environmental Safety and Health, of the U. S. Department of Energy and was performed in the Computer Science and Mathematics Division (CSMD) at the Oak Ridge National Laboratory, which is managed by UT-Battelle, LLC under Contract No. DE-AC05-00OR22725. Additional funding and oversight have been provided by the National Institute for Occupational Safety and Health (NIOSH) through Contract No ERD-03-2274 from Oak Ridge Associated Universities (ORAU) to support the NIOSH Office of Compensation Analysis and

The authors thank B. Jolene Jones of ORAU's Center for Epidemiologic Research and Lois Thurston in CSMD for their assistance in manuscript preparation. The work has been authored by a contractor of the U.S. Government. Accordingly, the U.S. Government retains a nonexclusive, royalty-free license to publish or reproduce the published form of this work, or to allow others to do so for U. S. Government purposes. 


\section{REFERENCES}

Aitchison, J. and J.A.C. Brown, 1969, The Lognormal Distribution, Cambridge, U.K., Cambridge University Press.

Akritas, M.G., T. F. Ruscitti, and G.S. Patil, 1994. Statistical Analysis of Censored Environmental Data, Handbook of Statistics, Vol. 12, G.P Patil and C.R. Rao (eds), 221-242, Elsevier Science, New York.

American Conference of Governmental Industrial Hygienists (ACGIH), Notice of Intended Change In: 2004 TLVs ${ }^{\circledR}$ and BEIs ${ }^{\circledR}$, p. 60, ACGIH, Cincinnati, OH.

Armstrong, B. G., 1992. "Confidence Intervals for Arithmetic Means of Lognormally Distributed Exposures," American Industrial Hygiene Association Journal, 53(8), 481-485.

Chambers, J. M., W. S. Cleveland, B. Kleiner and P. A. Tukey, 1983. Graphical Methods for Data Analysis, Duxbury Press, Boston.

Clopper, C. J. \& Pearson, E. S. (1934). The Use of Confidence or Fiducial Limits Illustrated in the Case of the Binomial. Biometrika_, 26, 404-413.

Cohen, A. C,. 1991. Truncated and Censored Samples. Marcel Dekker, Inc., New York.

Crow, E. L. and K. Shimizu, 1988. Lognormal Distribution, Marcel Decker, New York.

Cox, D. R. and D. V. Hinkley, 1979. Theoretical Statistics. Chapman \& Hall, New York.

Cox, D.R. and D. Oakes, 1984. Analysis of Survival Data. Chapman and Hall, New York.

Department of Energy, 10 CFR Part 850, Chronic Beryllium Disease Prevention Program, Federal Register, Vol. 64, No. 235, 68854-68914, December 1999.

Fowlkes, E. B. 1979. "Some Methods for Studying the Mixture of Two Normal (Lognormal) Distributions," Journal of the American Statistical Association, 74, 561-575.

Hahn, G.J. and W.Q. Meeker, 1991. Statistical Intervals. John Wiley and Sons, New York.

Hewett, P. and G. H. Ganser, 1997. "Simple Procedures for Calculating Confidence Intervals Around the Sample Mean and Exceedance Fraction Derived from Lognormally Distributed Data," Applied Occupational and Environmental Hygiene, 12(2), 132-147.

Helsel, D.,1990. "Less Than Obvious: Statistical Treatment of Date Below the Detection Limit", Environmental Science and Technology, 24(12), 1767-1774.

Hesel, D.R, and T.A. Cohn ,1988, "Estimation of Descriptive Statistics for Multiply Censored Water Quality Data", Water Resoureces Research, 24, 1997-2004.

Johnson, N. L. and B. L. Welch, 1940. "Application of the Non-Central t-Distribution," Biometrika, $31(3 / 4), 362-389$.

Kalbfleisch, J.D. and R.L. Prentice, 1980. The Statistical Analysis of Failure Time Data. John Wiley and Sons, New York.. 
Kaplan, E. L. and P. Meir, P.,1958. "Nonparametric Estimation from Incomplete Observations,” Journal of the American Statistical Association, 457-481.

Land, C. E., 1972. "An Evaluation of Approximate Confidence Interval Estimation Methods for Lognormal Means," Technometrics, 14(1), 145-158.

Meeker, W.Q and L.A. Escobar, 1998. Statistical Methods for Reliability Data. John Wiley and Sons, New York.

Moulton, L.H. and N.A. Halsey, 1995. "A Mixture Model with Detection Limits for Regression Analysis of Antibody Response on Vaccine," Biometrics, 51, 1570-1578.

Mulhausen, J. R. and J. Damiano, 1998. A Strategy for Assesing and Managing Occupational Exposures, Second Edition, AIHA Press, Fairfax, VA.

Neuman, M.C., P.M. Dixon, B.B. Looney,and J.E. Pinder, 1989, "Estimating Mean and Variance for Environmental Samples with Below Detection Limit Observations, Water Resources Bulletin,25, 905916.

Odeh, R. E. and D. B. Owen, 1980. Tables for Normal Tolerance Limits, Sampling Plans, and Screening, Marcel Deker, New York.

R Development Core Team (2004). R: A language and environment for statistical computing. R Foundation for Statistical Computing, Vienna, Austria. ISBN 3-900051-00-3, URL http://www.Rproject.org.

Schmee, J., D. Gladstein and W. Nelson, 1985. "Confidence Limits for Parameters of a Normal Distribution From Singly Censored Samples, Using Maximum Likelihood.” Technometrics, 27, 119-128.

Schmoyer, R. L., J. J. Beauchamp, C. C. Brandt and F. O. Hoffman, Jr., 1996. "Difficulties with the Lognormal Model in Mean Estimation and Testing," Environmental and Ecological Statistics, 3, 81-97.

Sommerville, P. N., 1958. "Tables for Obtaining Non-Parametric Confidence Limits," Annals of Mathematical Statistics, 29, 599-601.

Taylor, D. J., L. L. Kupper, S. M. Rappaport, and R. H. Lyles, 2001. "A Mixture Model for Occupational Exposure Mean Testing with a Limit of Detection”, Biometrics, 57, 681-688.

Tuggle, R. M., 1982. “Assessment of Occupational Exposure Using One-Sided Tolerance Limits,” American Industrial Hygiene Association Journal, 43, 338-346.

Turnbull, B. W., 1976. "The Empirical Distribution Function with Arbitrarily Grouped, Censored and Truncated Data," Journal of the Royal Statistical Society, Series B (Methodological), 38(3), 290-295.

Venables, W. N. and B. D. Ripley, 2002. "Modern Applied Statistics with S," $4^{\text {th }}$ edition. SpringerVerlag, New York.

Verrill, S. and R. A. Johnson, 1998. "Tables and Large-Sample Distribution Theory for Censored-Data Correlation Statistics for Testing Normality," Journal of the American Statistical Association, 83(404), 1192-1197.

Waller, L. A., and B. W. Turnbull, 1992. "Probability Plotting with Censored Data," The American Statistician, 46(1), 5-12. 


\section{APPENDIX}

$\mathrm{R}$ (2004) is available as Free Software under the terms of the Free Software Foundation's GNU General Public License in source code form. It compiles and runs on a wide variety of UNIX platforms and similar systems (including FreeBSD and Linux), Windows and MacOS. Detailed documentation on all aspects of $\mathrm{R}$ is available at the $\mathrm{R}$ home page http://www.r-project.org/. Sources, binaries, and documentation for R can be obtained via CRAN, the "Comprehensive R Archive Network" (click on CRAN on the $\mathrm{R}$ home page menu ). An Introduction to $\mathrm{R}$ and related manuals edited by the $\mathrm{R}$ Development Core Team are provided under the "Manuals" link. Additional manuals, tutorials, etc. are provided by users of R under the "Contributed" Link. References are provide under the "Publications" link. [Venables and Ripley(2002)] is a highly recommended book on statistical data analysis using R. All of the $\mathrm{R}$ functions discussed in this report and the data used in the examples in Section 4 are available at the website http://www.csm.ornl.gov/esh/aoed (AOED). Most of the serious computing is done by R base functions optim and uniroot. The $\mathrm{R}$ driver functions at AOED are provided to assist the reader that may not have experience with R. They are not "formal" $\mathrm{R}$ functions, i.e. there is limited error checking and the usual type of R online "help" files are not provided. Documentation for each function is provided in this report and as comments in the function. All of the files at the AOED web site are ascii (txt) files and can be modified using any text editor (e.g. xemacs, wordpad, vi). The most important functions with more detailed documentation are combined into one file oedmain.R (Exhibit 3). Additional functions that reflect the authors' interest and that may require revisions for other applications are also provided in the file oedutil.R (Exhibit 4). Both of these are available at the AOED web site the AOED website.

In Section 4 several examples of the interactive use of these functions for the analysis of left censored data were provided. These functions can be used for complete data sets by providing an input matrix with the data in column 1 and the censoring indicator for each data value (all equal to 1 ) in column 2 . The results will be the ML estimates. For complete data sets when $\mathrm{n}$ is small the "exact " results described in Section 2 may be of interest. The R function Inexact in Exhibit 2 illustrates the use of the functions (see Exhibit 3) extol and efcl for the exact analysis of complete samples. It is used here to provide an introduction to R (see below). These functions are appropriate for complete data sets when the "upper tail" of the lognormal distribution is of interest (see Mulhausen and Damiano, 1998 Appendix VII). In this situation the industrial hygienist picks an upper percentile $X_{p}$ (often the $95^{\text {th }}$ percentile) and specifies a limit $\mathrm{L}_{\mathrm{p}}$ (e.g., the $\mathrm{OEL}$ ). The value of $\mathrm{p}$ is the minimum proportion of the exposure distribution that must fall below the limit $\mathrm{L}_{\mathrm{p}}$ for the exposure profile to be considered "acceptable." The exact $100 \gamma \%$ upper confidence limit for the pth percentile $X_{p}$ is $\operatorname{UX}(p, \gamma)=\exp \left(\bar{y}+K s_{y}\right)$ and is referred to as the upper tolerance limit ( see Section 2.2). The exact $100 \gamma \%$ lower confidence limit for $\mathrm{X}_{\mathrm{p}}$ is $\mathrm{LX}(\mathrm{p}, \gamma)=$ $\exp \left(\overline{\mathrm{y}}+\mathrm{K}^{\prime} \mathrm{s}_{\mathrm{y}}\right)$. The point estimate of the exceedance fraction $\mathrm{F}_{\mathrm{L}}$ and $100 \% \%$ lower and upper confidence limits are calculate using efcl(x,gam,L) as described in Section 2.3. The Sapiro-Wilk W statistic recommended by AIHA can be used on complete data sets using R function shapiro.test for $\mathrm{n}$ between 3 and 5000.

To duplicate the results that follow visit the AOED web site and complete steps 1-4. The R working directory AIHD will contain all of the functions described in this report and data frames aiha (example data from Mulhausen and Damiano, 1998, page 259) and aihand (example data from Mulhausen and Damiano, 1998, page 244 with 3 non-detected values). Note that aihand is used as the default data set in all functions that require a two column matrix or data frame (e.g., mIndln). The input to

$\operatorname{lnexact}(\mathbf{x}, p, \operatorname{gam}, L)$ in Exhibit 2 is a vector $\mathbf{x}$ of positive data $x_{i}, i=1, \ldots, n$, and the values of $p, \operatorname{gam}(\gamma)$, and $\mathrm{L}$. The first line is the function name and arguments. Lines 2-18 are comments that describe what the function does, the arguments, and the values returned. All characters on a line to the right of the \# sign are comments. In a formal $\mathrm{R}$ function this information is obtained from a "help" file by entering ? followed by the name of the function; e.g, typing $\mathbf{p t}$ at the R prompt ( the symbol $>$ ) describes the probability density function for Student's t distribution that is used by extol and efcl. Line 20 describes 
the error check on line 21. The mean and standard deviation of $y=\log (x)$ and sample size are calculated on line 23 (note that the semicolon separates executable statements on the same line). The next 3 lines calculate the point estimate and confidence limits for $\mathrm{X}_{\mathrm{p}}$ using extol to calculate the values of $\mathrm{K}$ and $\mathrm{K}^{\prime}$. Line 27 combines the three values into a vector $\mathbf{x p}$ and names it $\mathbf{n p . ~ L i n e ~} 28$ uses efcl to calculate the point estimate and confidence limits for the exceedance fraction, and the next line combines vector $\mathbf{x p}$ and $\mathbf{f p}$ into a data frame with names based on the input values of $\mathrm{p}$, gam, and $\mathrm{L}$. These functions can be revised using the $\mathrm{R}$ functions fix or edit, or by using a text editor (e.g., Notepad or XEmacs) to make a new file.

\section{Exhibit 2 in the Appendix}

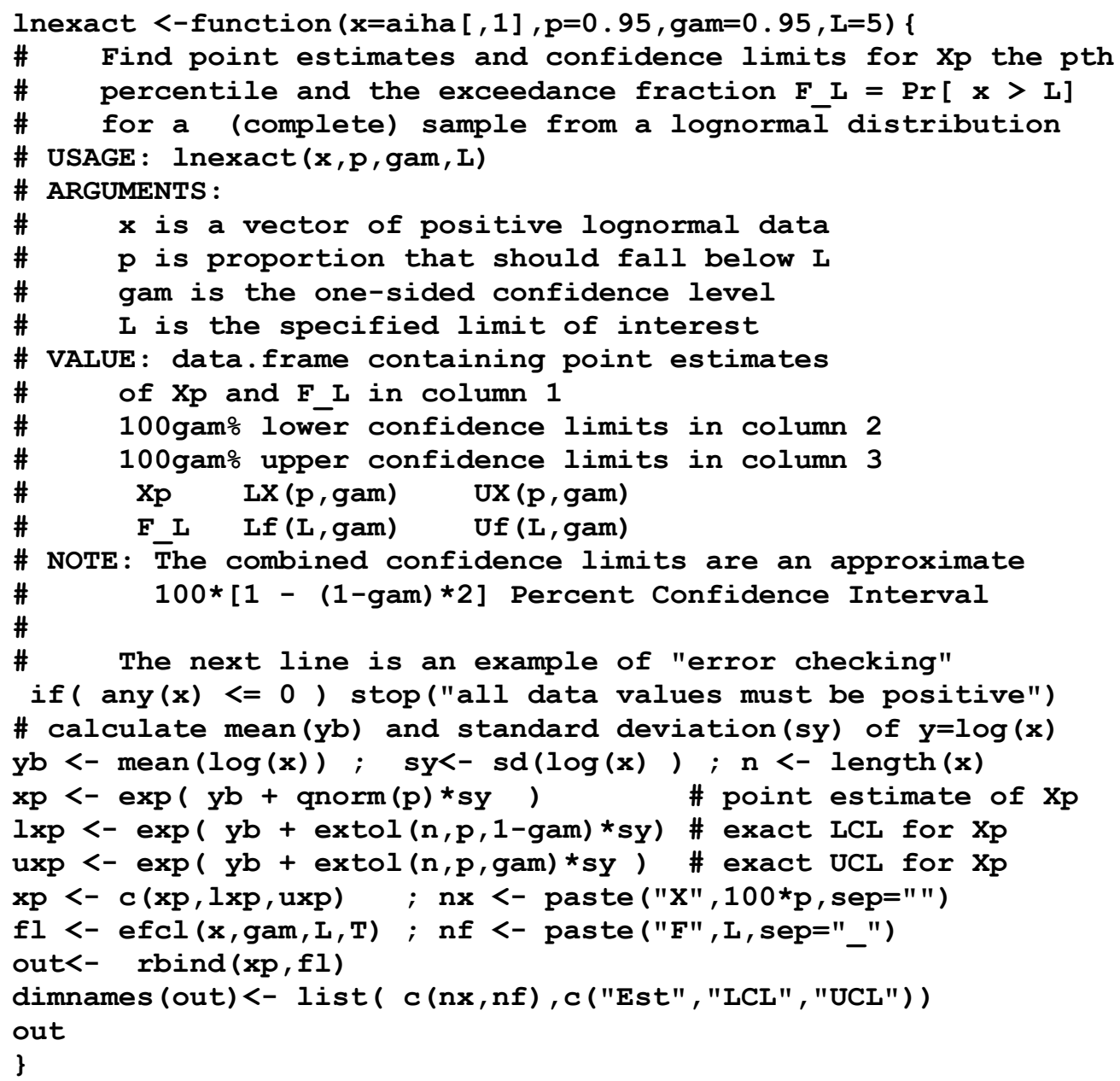


The following script demonstrates the use of Inexact

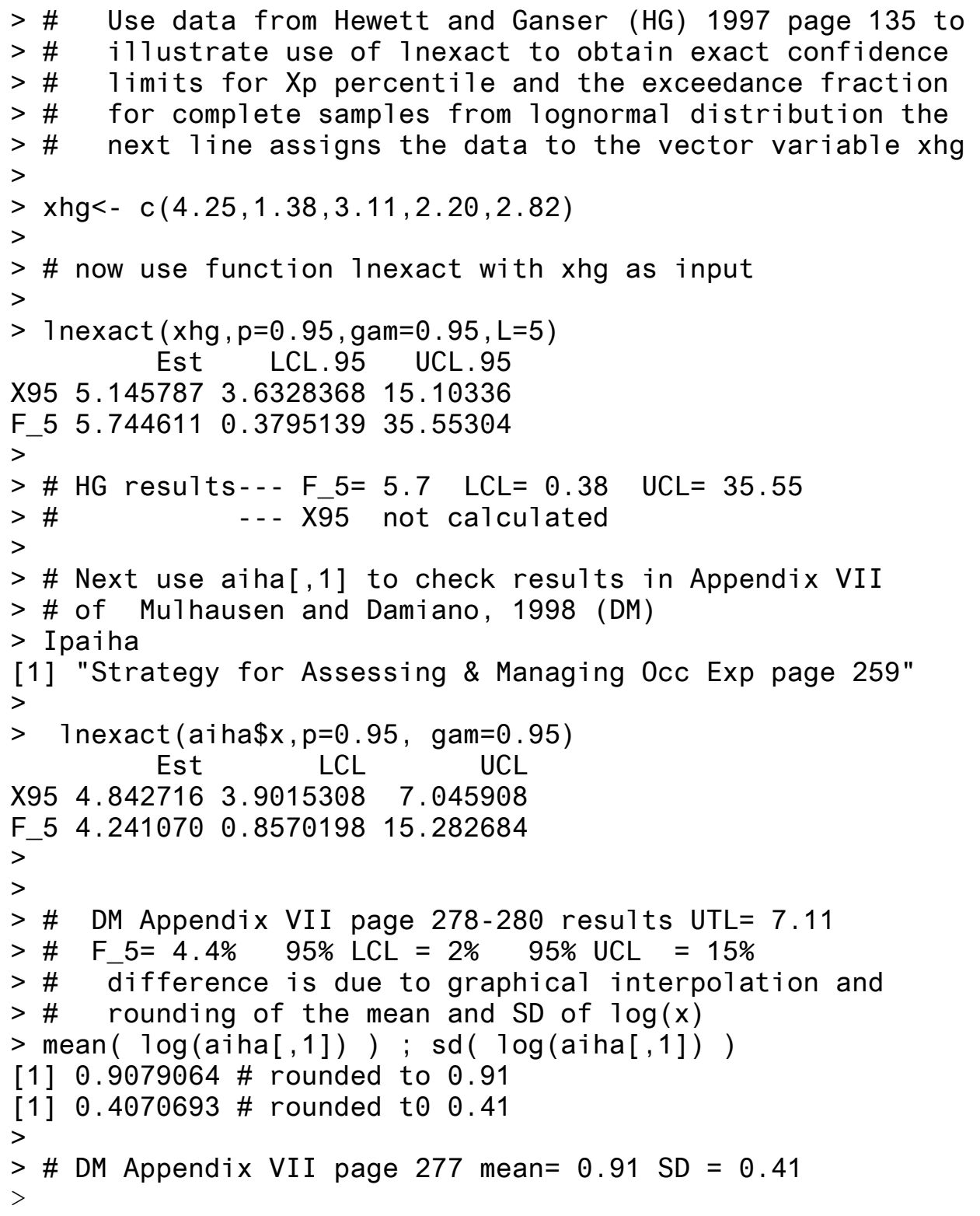

The results from Inexact will agree with those from Odeh and Owen for any reasonable values of $\mathrm{p}$, gam, and $\mathrm{L}$. Note that if the value of $\mathrm{L}$ is changed to the $95 \% \mathrm{UCL}$ for Xp

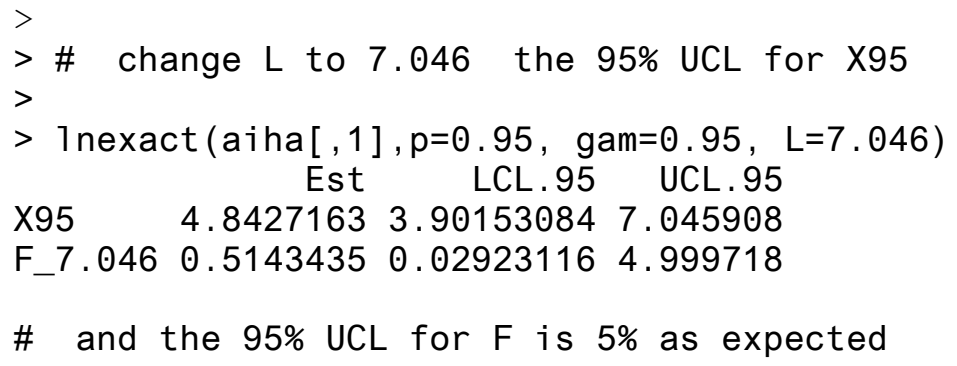


This shows the equivalance of the relationship between the upper tolerance limit and the exceedance fraction; i.e, with $\gamma=0.95, \mathrm{p}=0.95, \mathrm{~L}=7.046, \mathrm{~F}_{0}=5 \%$ the upper tolerance limit is $\operatorname{UX}(0.95,0.95)=$ 7.04559 and the upper confidence limit for the exceedance fraction is $\operatorname{Uf}(7.046,0.95)=4.99972$

$$
\begin{array}{lll}
\mathrm{H}_{0}: \mathrm{X}_{\mathrm{p}} \geq \mathrm{L} & \text { reject if } \mathrm{UX}(\mathrm{p}, \gamma)<\mathrm{L} & \text { REJECT } \mathrm{H}_{0} \\
\mathrm{H}_{0}: \mathrm{F}_{\mathrm{L}} \geq 1-\mathrm{p} & \text { reject if } \mathrm{Uf}(\mathrm{L}, \gamma)<\mathrm{F}_{0} & \text { REJECT } \mathrm{H}_{0}
\end{array}
$$

Likewise, if the value $p=1-$ UCLF_5/100 $=.8472$ is used

$$
\begin{aligned}
& >\text { \# change } p \text { to } 1-0.1528=0.8472 \\
& > \\
& >1 \text { nexact (aiha }[, 1], p=0.8472, \text { gam }=0.95, L=5 \text { ) } \\
& \text { Est LCL.95 UCL.95 } \\
& \begin{array}{llll}
X 84.72 & 3.76199 & 3.1313547 & 5.000301
\end{array} \\
& \begin{array}{lllll}
\text { F_5 } & 4.24107 & 0.8570198 & 15.282684
\end{array} \\
& >\text { \# and the } 95 \% \text { UCL for Xp is } 5 \text { as expected }
\end{aligned}
$$

This is equivalent to $\gamma=0.95, \mathrm{p}=0.8472, \mathrm{~L}=5, \mathrm{~F}_{0}=15.29 \%$, the upper tolerance limit is $\mathrm{UX}(0.847,0.95)=4.999157$, and the upper confidence limit for the exceedance fraction is $\mathrm{Uf}(5,0.95)=$ 15.282684

$$
\begin{array}{lll}
\mathrm{H}_{0}: X_{\mathrm{p}} \geq \mathrm{L} & \text { reject if } \mathrm{UX}(\mathrm{p}, \gamma)<\mathrm{L} & \text { REJECT } \mathrm{H}_{0} \\
\mathrm{H}_{0}: \mathrm{F}_{\mathrm{L}} \geq 1-\mathrm{p} & \text { reject if } \mathrm{Uf}(\mathrm{L}, \gamma)<\mathrm{F}_{0} & \text { REJECT } \mathrm{H}_{0}
\end{array}
$$

\section{Exhibit 3 in the Appendix}

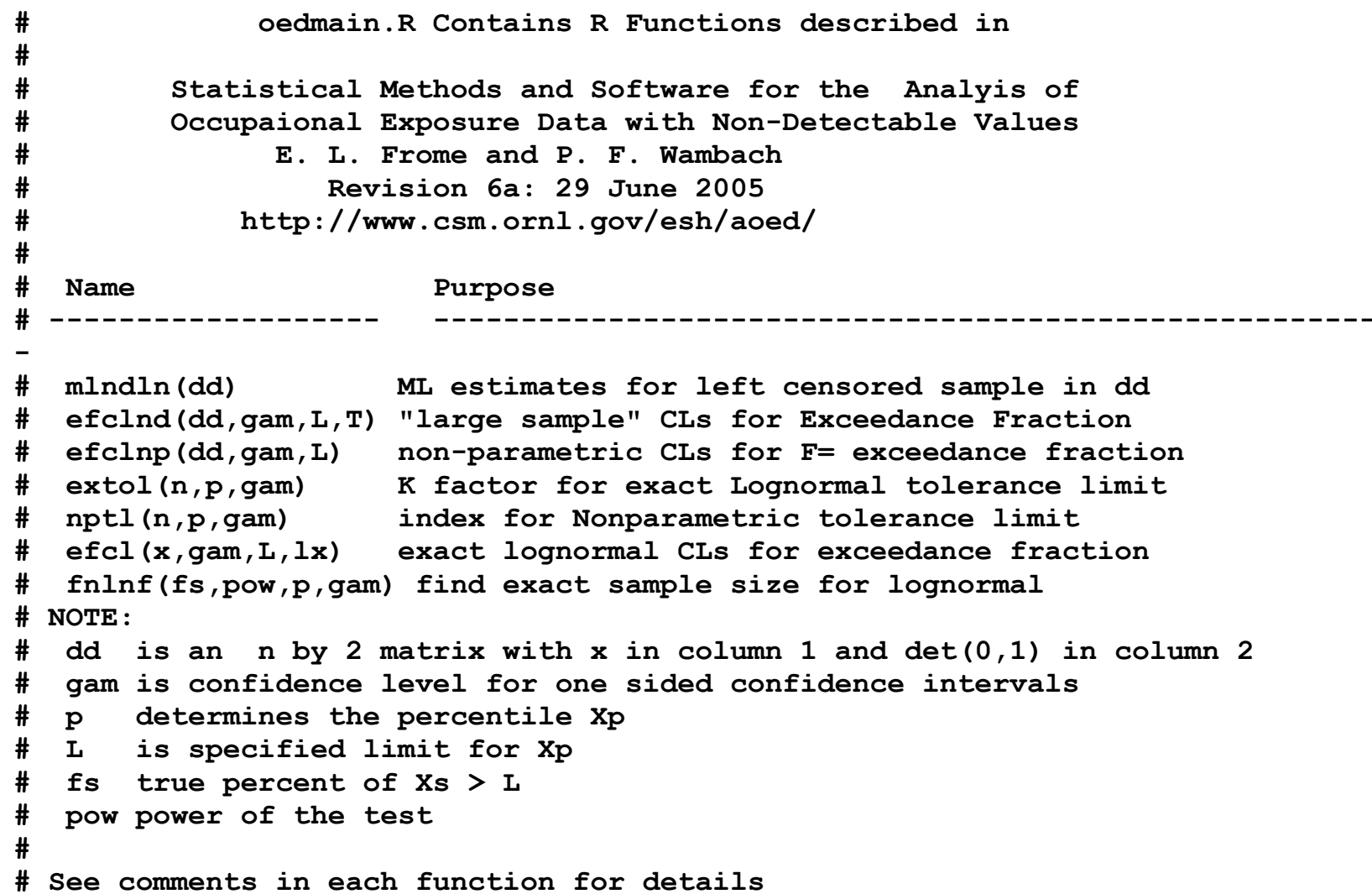




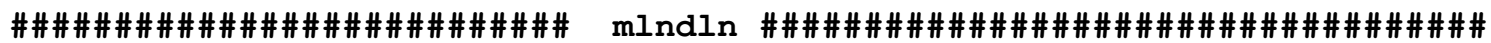
mlndln <- function (dd = aihand ) \{

\# ML estimates for lognormal sample with non-detects see Section 3

\# USAGE : mlndln ( dd )

\# ARGUMENT: matrix dd with $x$ [i] in column 1 and $\operatorname{det}[i]$ in col 2

\# $\quad \mathbf{x}[i]$ is positive lognormal data

\# $\operatorname{det}[i]=0$ for non-detect ; 1 for detect

\# NOTE:

\# $\quad y=\log (x)$ is normal with mean mu and standard deviation sigma

$\# \quad E(X)=\exp \left(\mathrm{mu}+0.5^{\star}\right.$ sig2 $)=\exp (\log E)$ where sig2 = sigma^2

\# $\quad \mathrm{m}$ is number of detects and Conver is convergence check

\# VALUE: ML estimates of following in 2 by 6 matrix format:

\# mu sigma loge sig2 -2Log(L) Conver

\# se.mu se.sigma se.loge se.sig2 cov(mu,sig) m

\# REFERENCE: Cohen, A.C (1991) Truncated and Censored Samples

\# Marcel Decker, New York

\# REQUIREs: ndln() ndln2() loglikelihood functions for optim()

\# $\quad$ see $R$ help file for details on optim() and dlnorm()

$\mathrm{m}<-$ sum(dd $[, 2]) \quad \#$ number of non-detects

\# initial estimate of $\mathrm{mu}$ and sig (sigma)

yt <- ifelse (dd $[, 2]==0$, dd $[, 1] / 2, \operatorname{dd}[, 1])$

est <-c( mean $(\log (y t)), \operatorname{sd}(\log (y t)))$

\# ML estimates mu and sig

est <- optim(est, ndln, method = c("Nelder-Mead"), xd=dd ) \$par

cont <- list (parscale=abs (est))

opt1 <- optim (est, ndln ,NULL, method ="L-BFGS-B", lower=c $(-$ Inf , 0.0), upper $=c$ (Inf, Inf), cont, hessian $=T, x d=d d$ )

conv1 <- opt1\$conv \# convergenc check from optim()

mle <- opt1\$par

vam <- solve (opt1\$hessian)

semle <- sqrt(diag( vcm )) \# standard Errors of mu and sig

cov <- vcm $[1,2]$ \# covariace (mu,sig) needed for Tolerance bound

$\#$

\# ML estimate of $\log E$ and sig2 (sigmma^2)

\#

est $[1]<-\operatorname{mle}[1]+0.5 * \operatorname{mle}[2]^{\wedge} 2$

est [2] <- mle[2]^2

cont <- list (parscale=abs (est))

opt2 <- optim(est, ndln2, NULL, method ="L-BFGS-B", lower=c (-Inf, 0.0), upper=c (Inf, Inf), cont, hessian $=T, \mathbf{x d}=\mathrm{dd}$ )

\# next line adds ML estimate of loge sig2 -2Log(L) and Conver

\# If Conver is not equal to 0 CHECK RESULTs--- see optim() help

mle <- c(mle, opt2\$par, 2*opt2\$value, opt2\$conv+conv1)

semle <- c(semle, sqrt (diag (solve (opt2\$hessian))), $\operatorname{vcm}[1,2], m)$

names (mle) <- c("mu", "sigma", "logE", "sig2","-2Log (L)", "Conver")

out <-rbind (mle, semle)

out

\}

\#

ndln <- function (p=est, $x d$ ) \{

\# - $\log$ likelihood functions for optim() in mlndln()

$\mathrm{mu}<-\mathrm{p}[1] ; \mathrm{sig}<-\mathrm{p}[2] ; \mathrm{x}<-\mathrm{xd}[, 1]$

$\mathbf{x x}<-i f e l s e(x d[, 2]==1, \operatorname{dlnorm}(x, m u, \operatorname{sig}, \log =T), \operatorname{plnorm}(x, m u, \operatorname{sig}, \log \cdot p=T))$

$-\operatorname{sum}(\mathbf{x x})$

\}

\# 


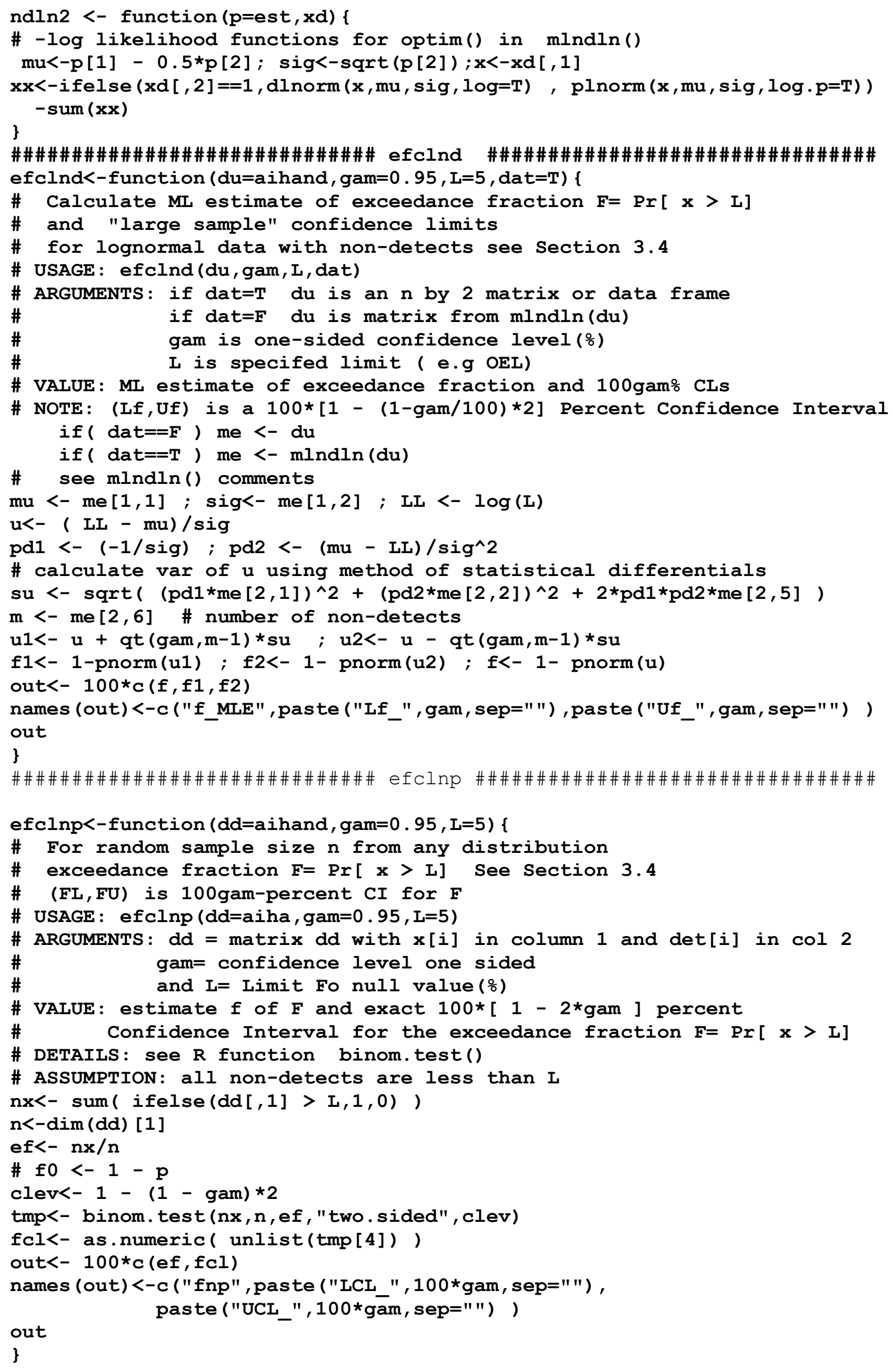




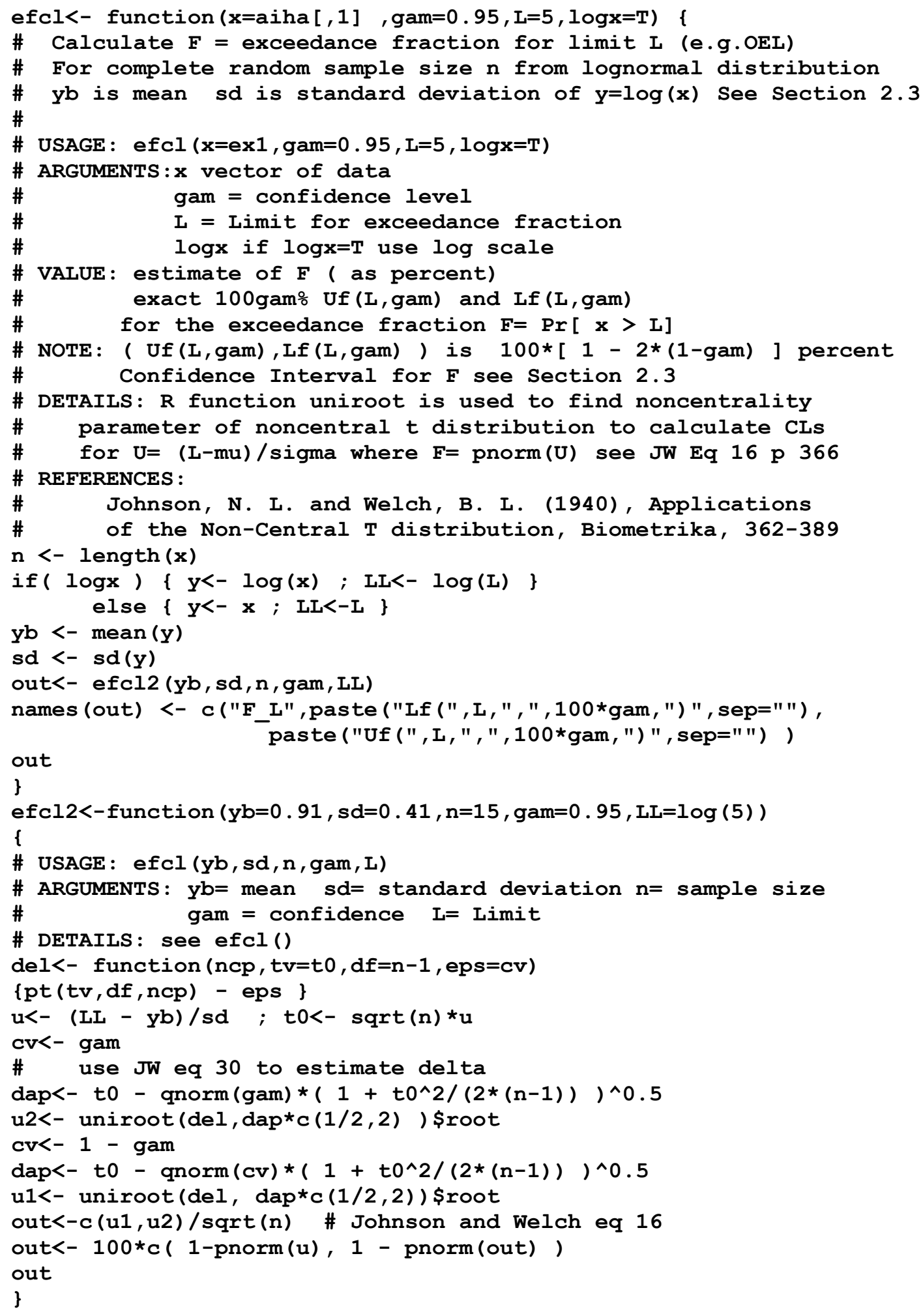




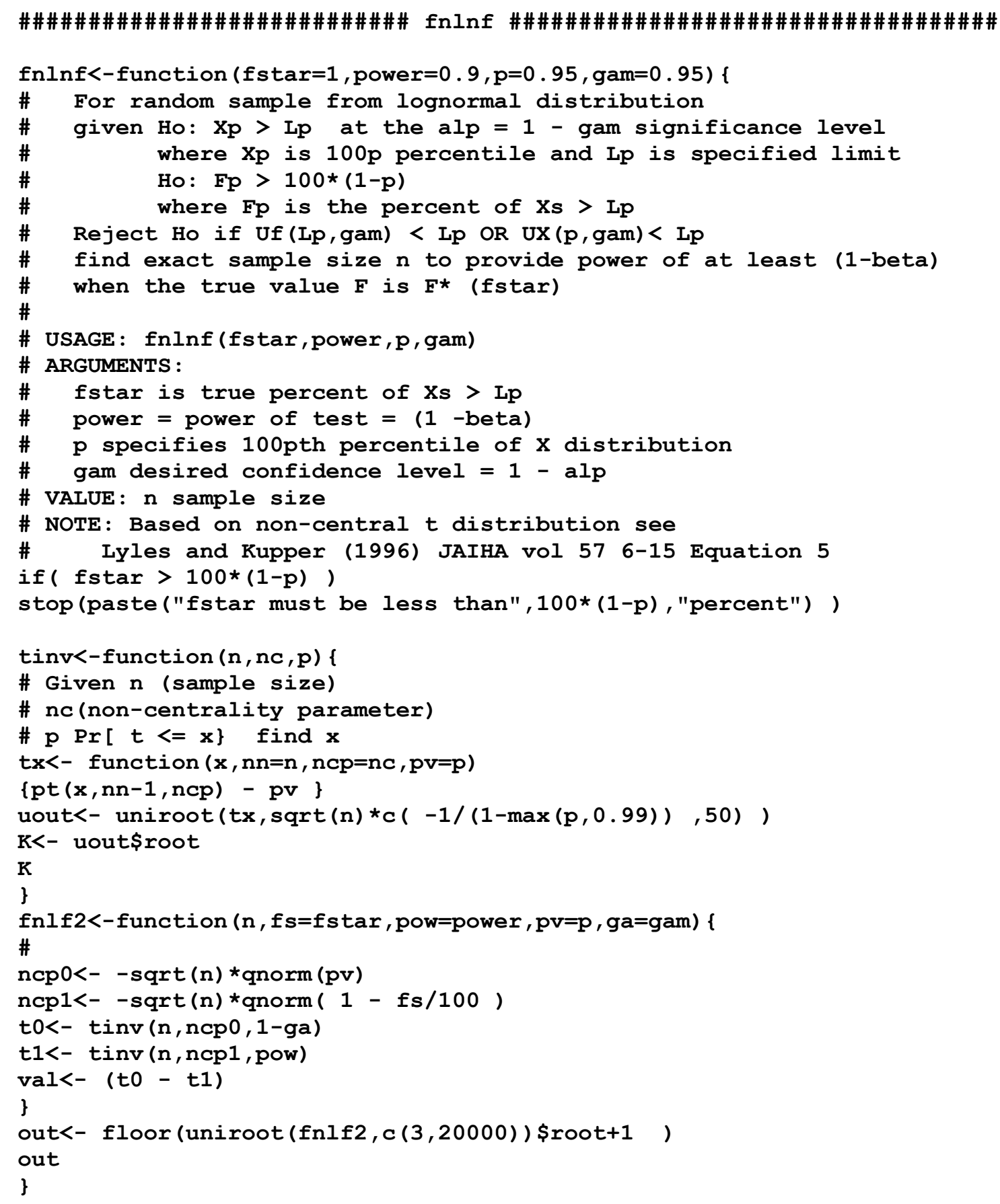

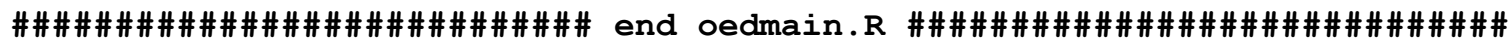




\section{Exhibit 4 in the Appendix}

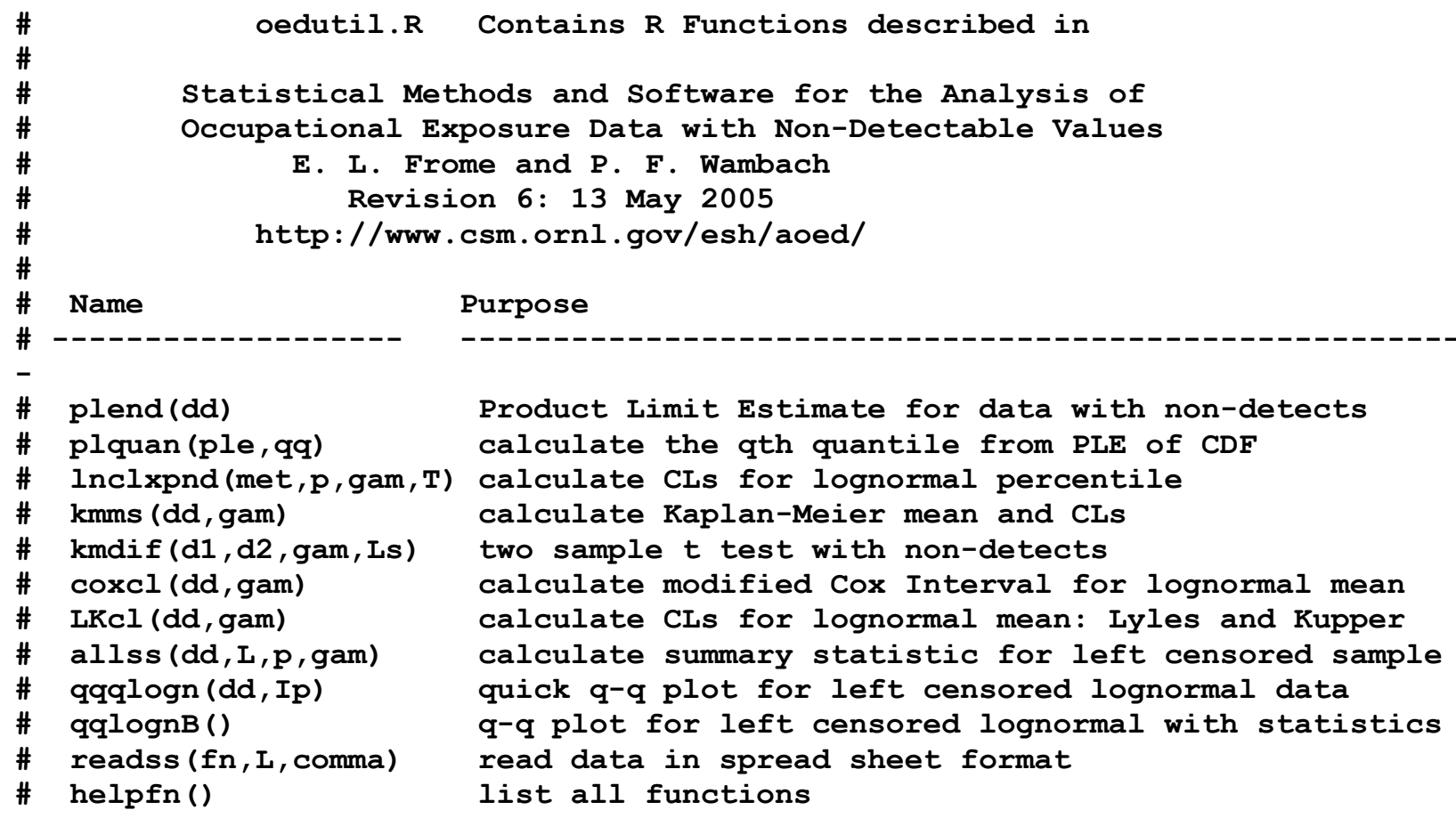

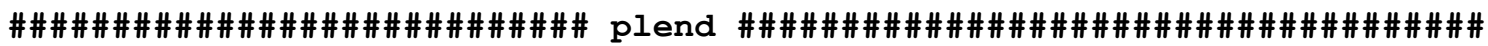

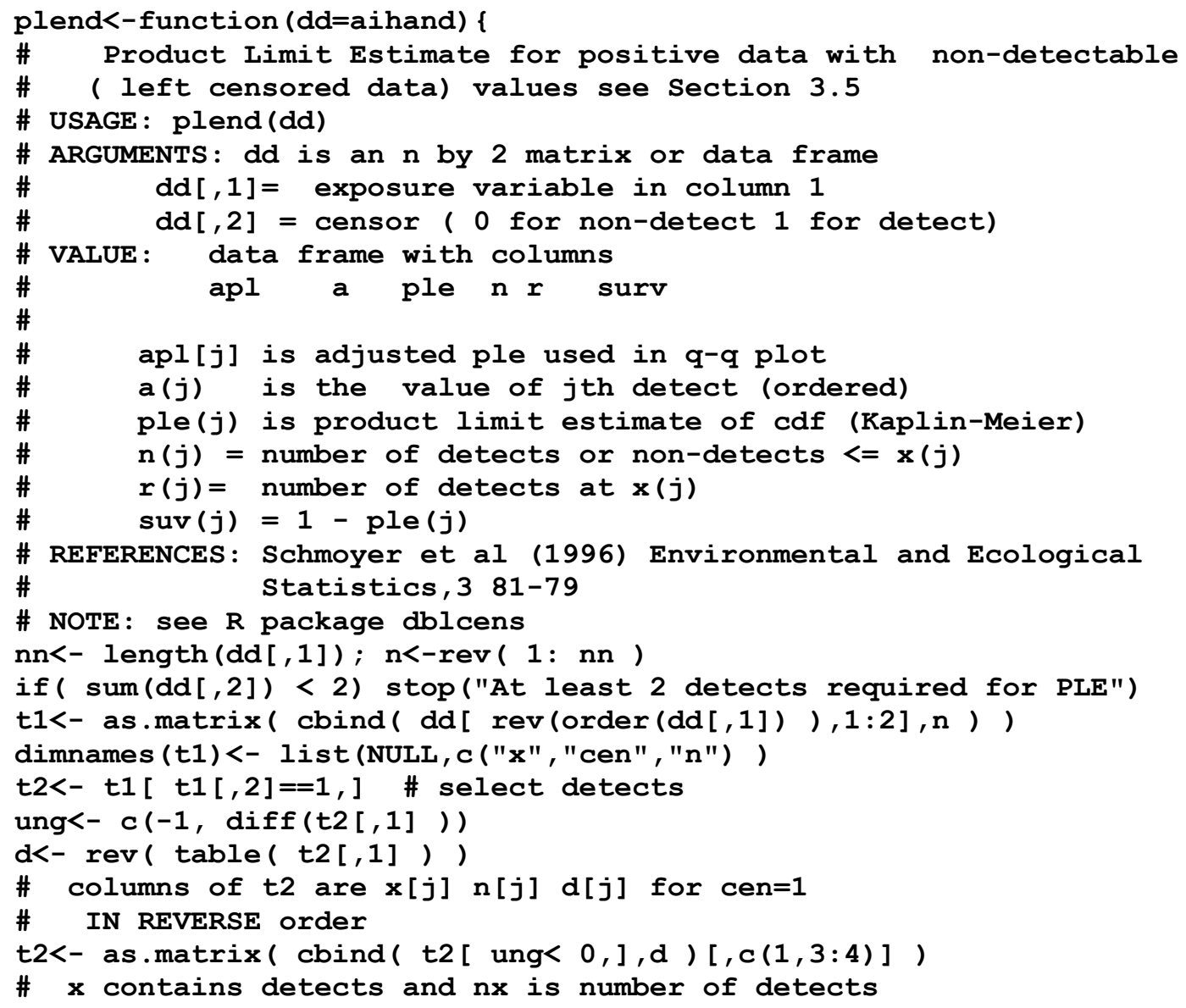




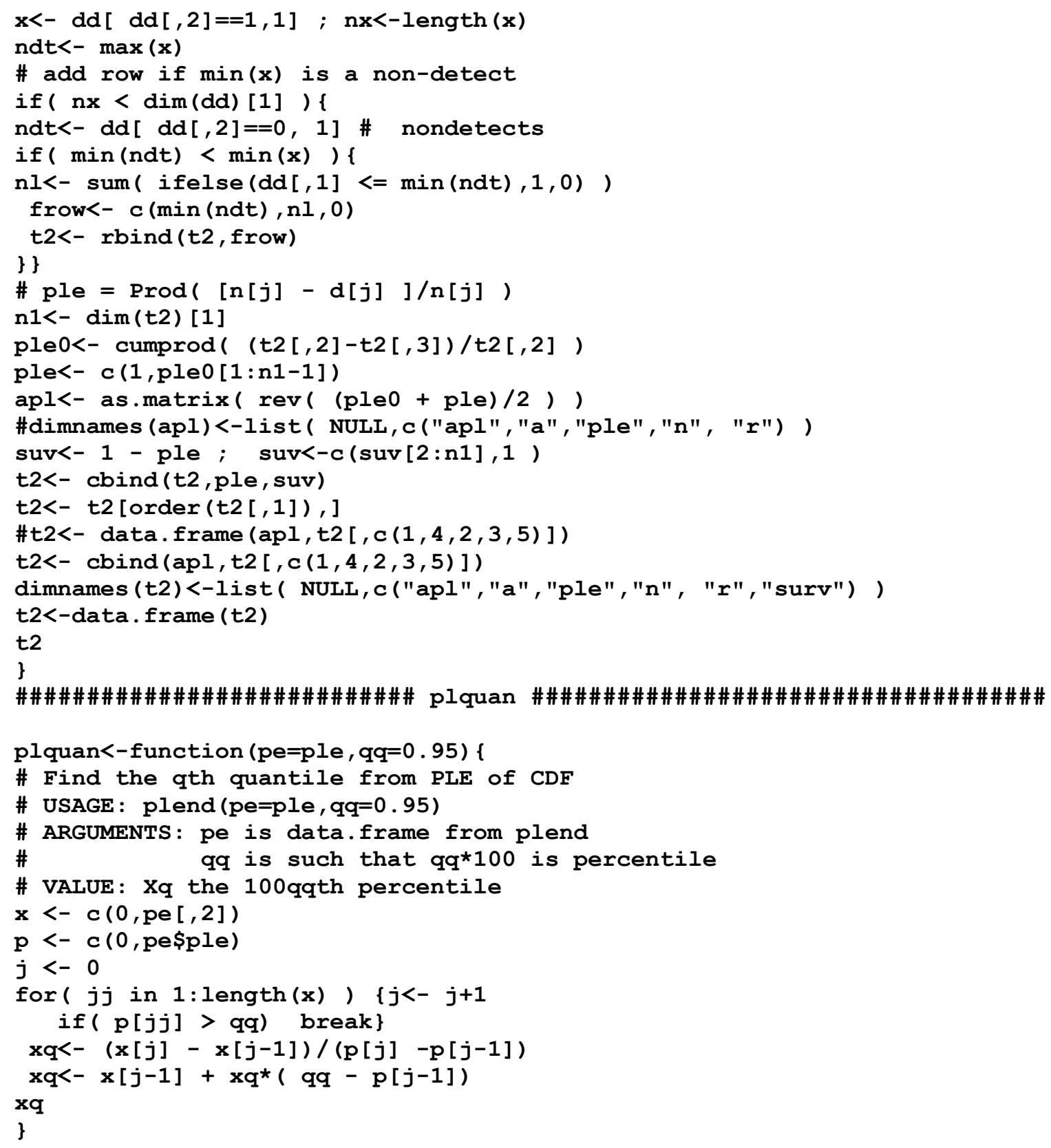

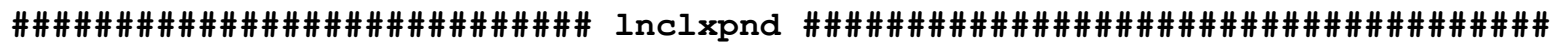

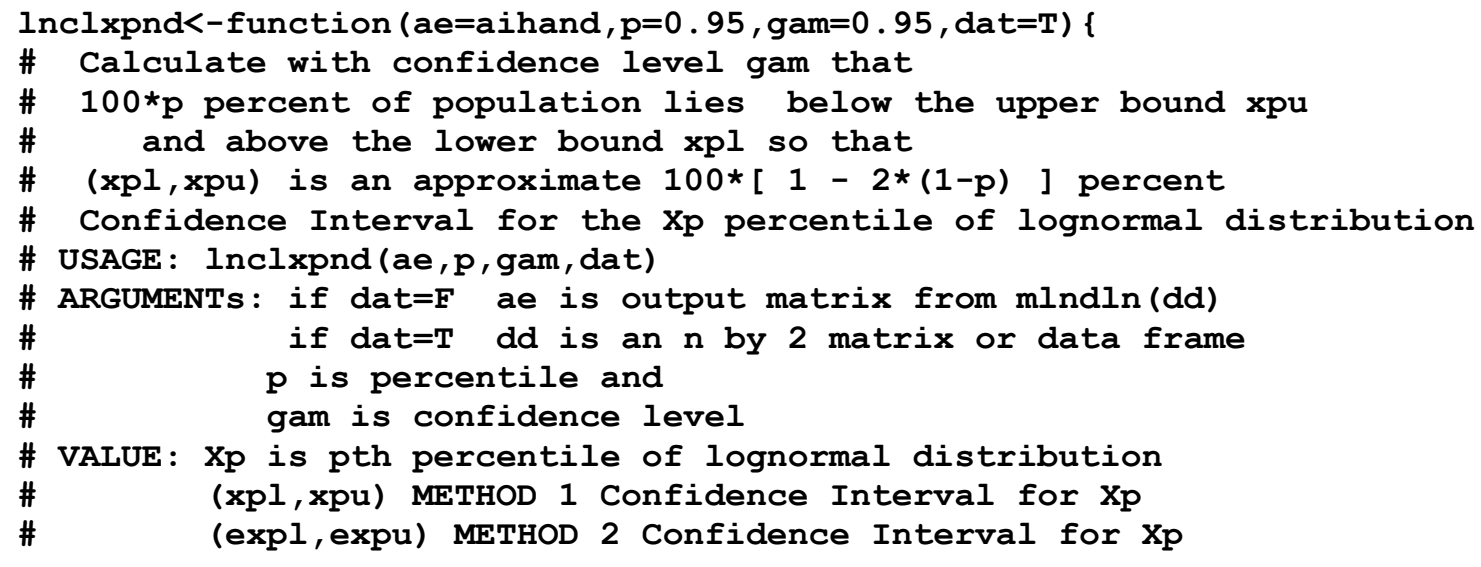




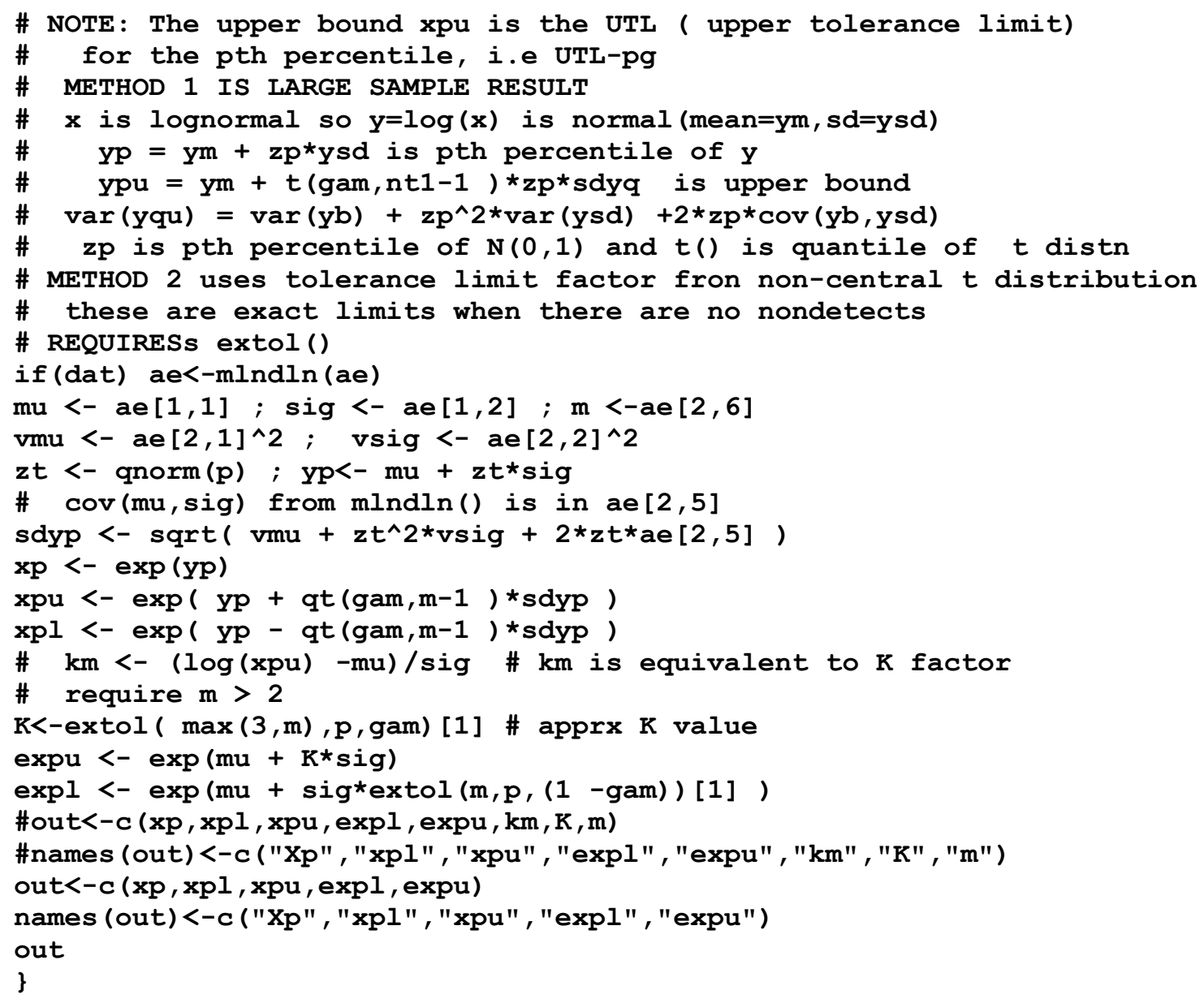

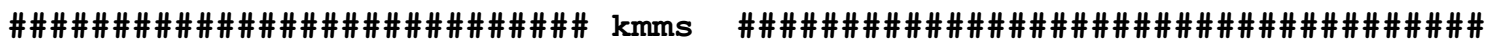

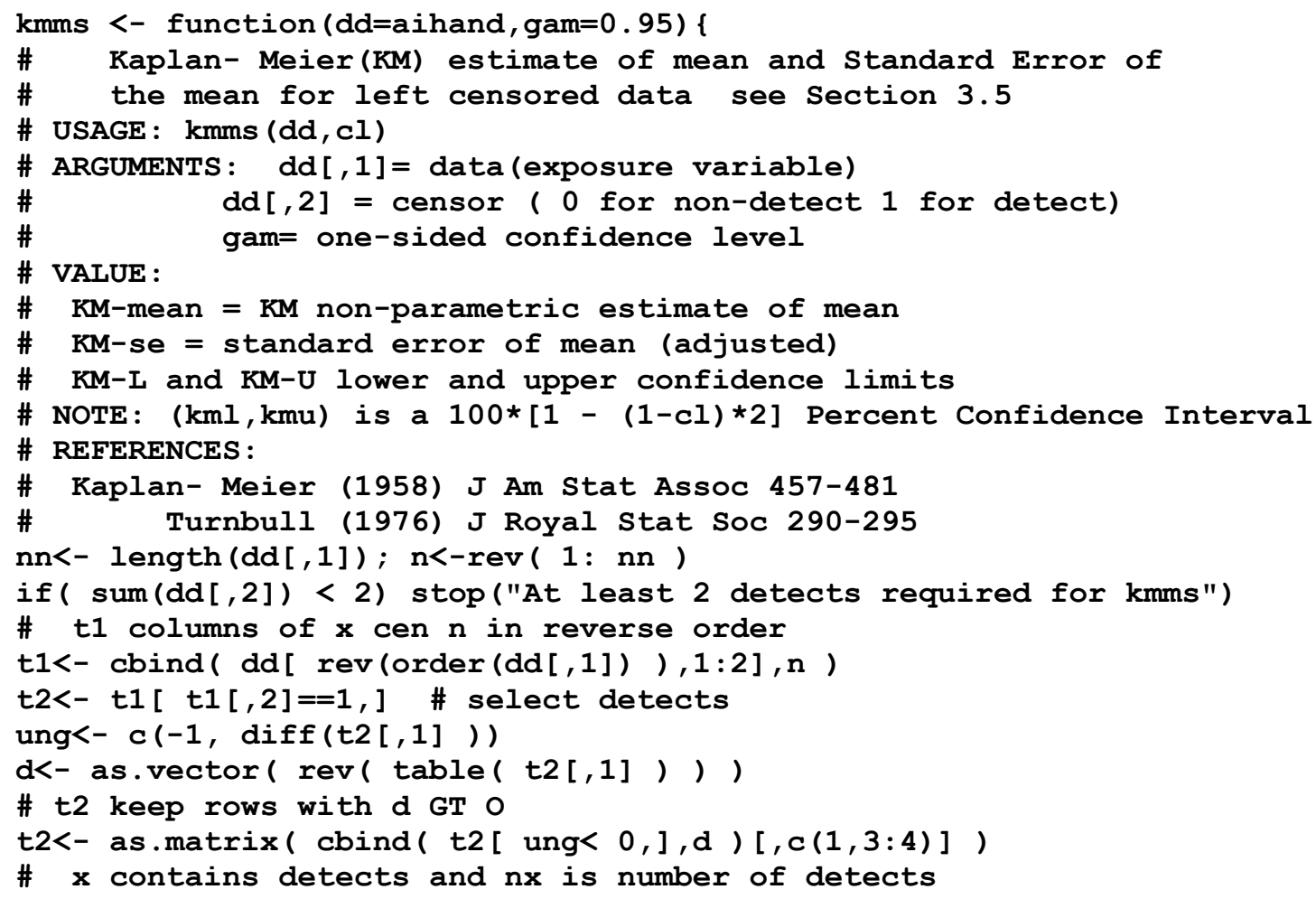




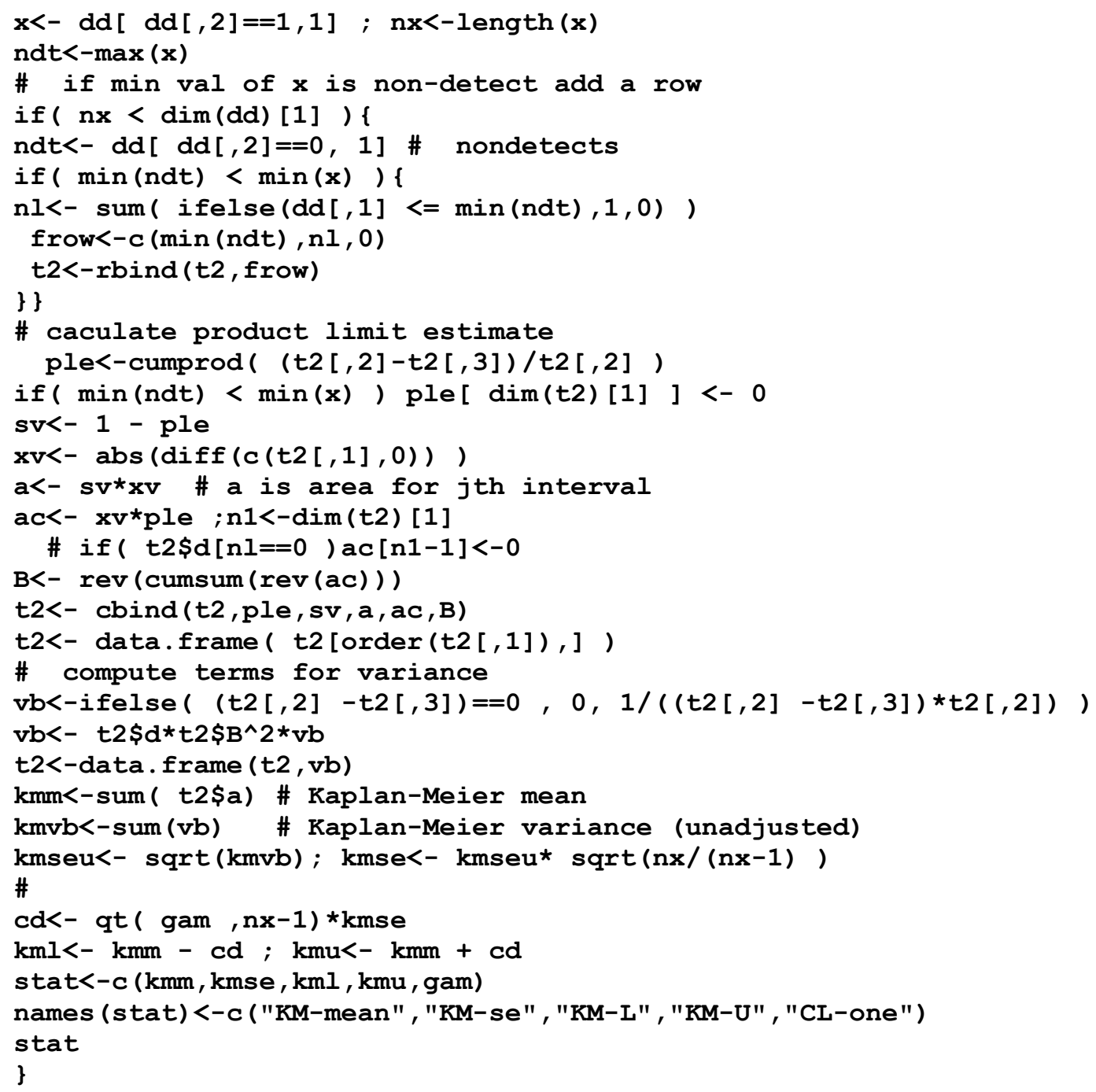




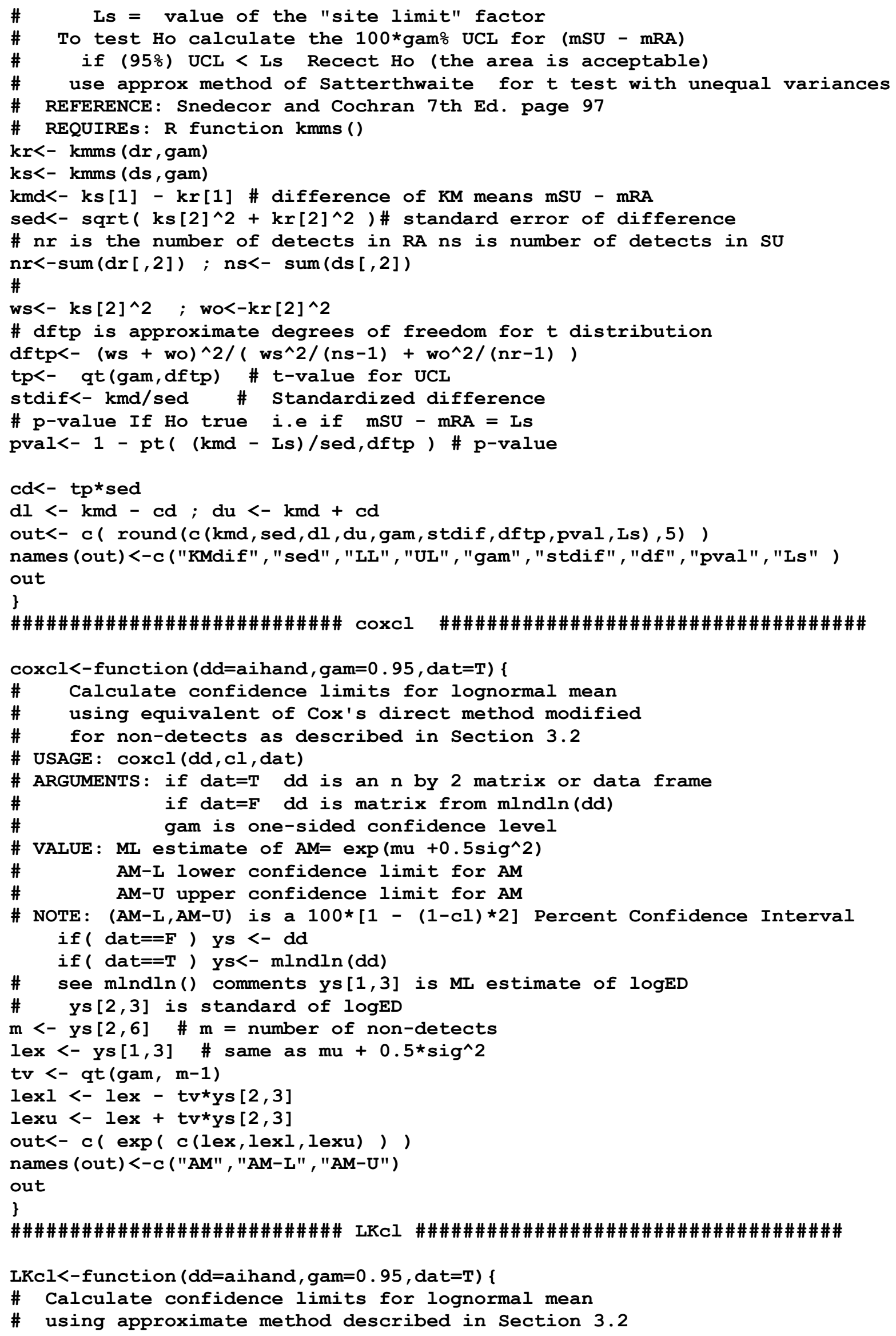




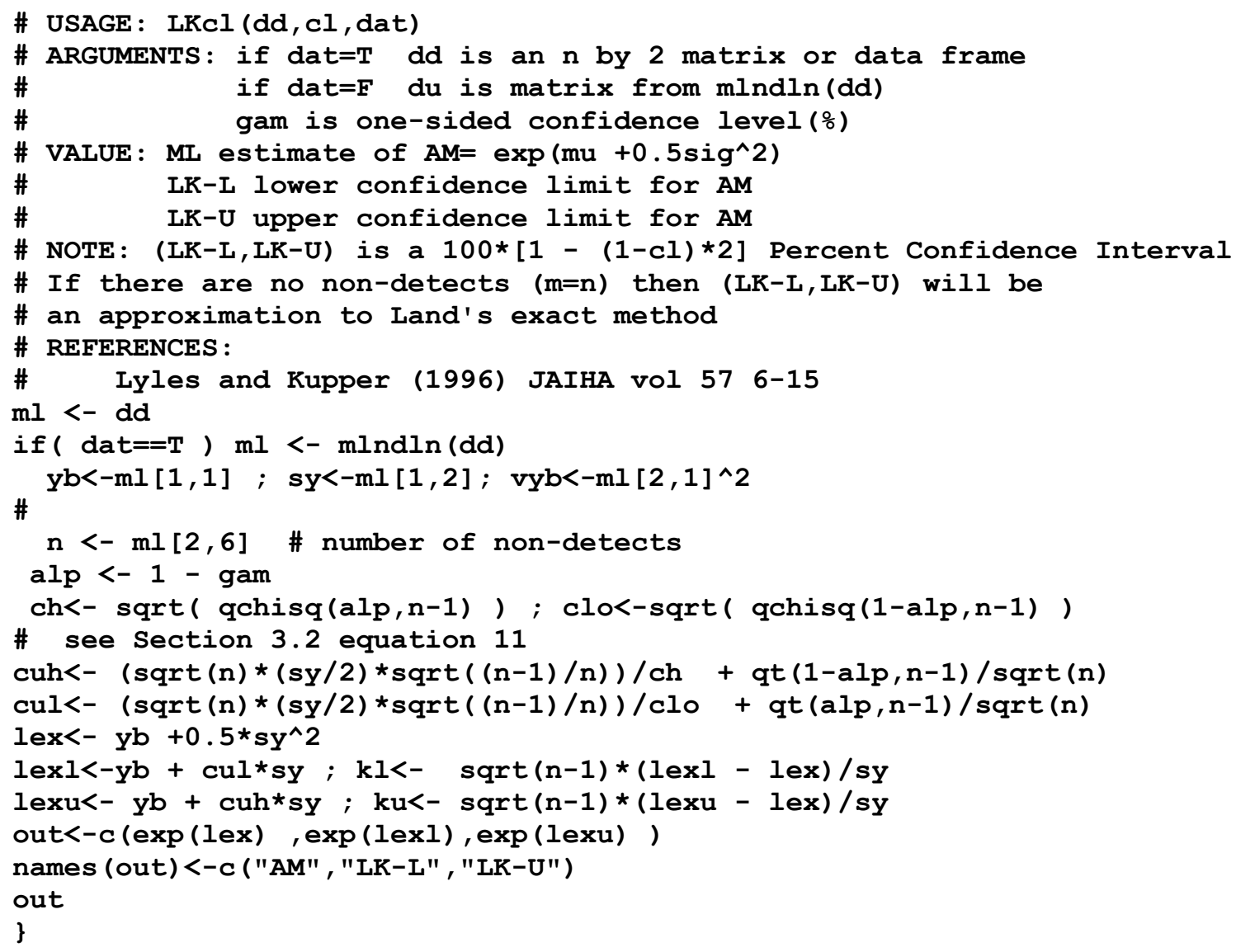

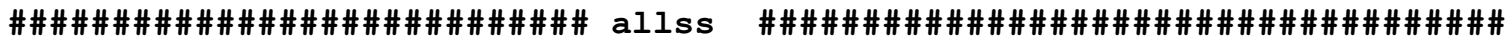
allss <- function (dd=aihand, $\mathrm{L}=5, \mathrm{pc}=0.95, \mathrm{gam}=0.95, \mathrm{mth}=1, \mathrm{ro}=3$ ) \{

\# Method 1 is equivalent to modified Cox direct Method

\# approximate CLs for lognormal mean

if (mth==1) \{clo<-coxcl (ys, gam, F)

$\mathrm{EX}<-\mathrm{clo}[1]$

EXL<-clo[2] ; nEXL=paste ("LCLa", 100*gam, sep="_") 


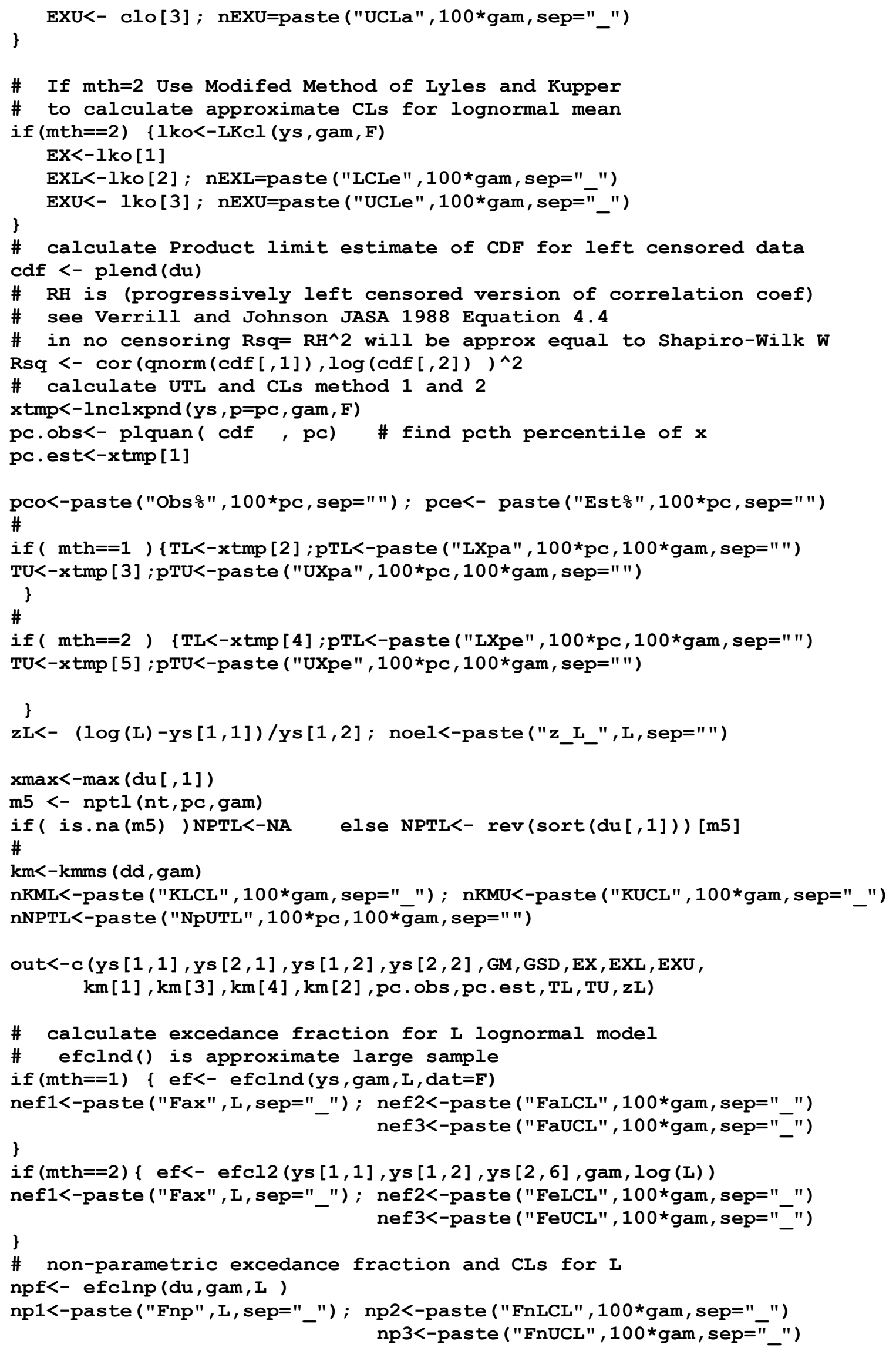




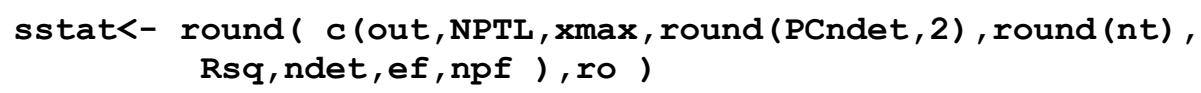




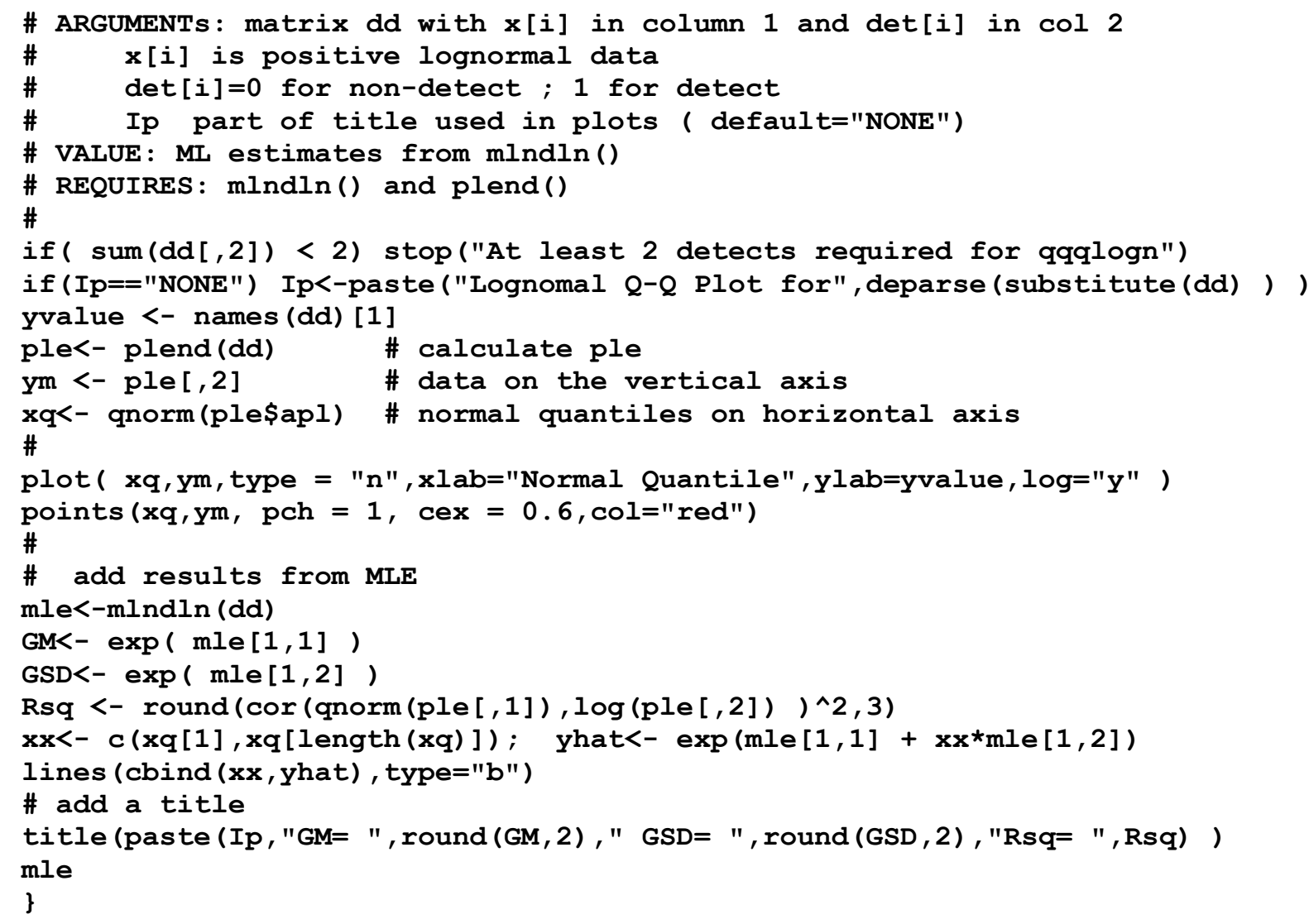




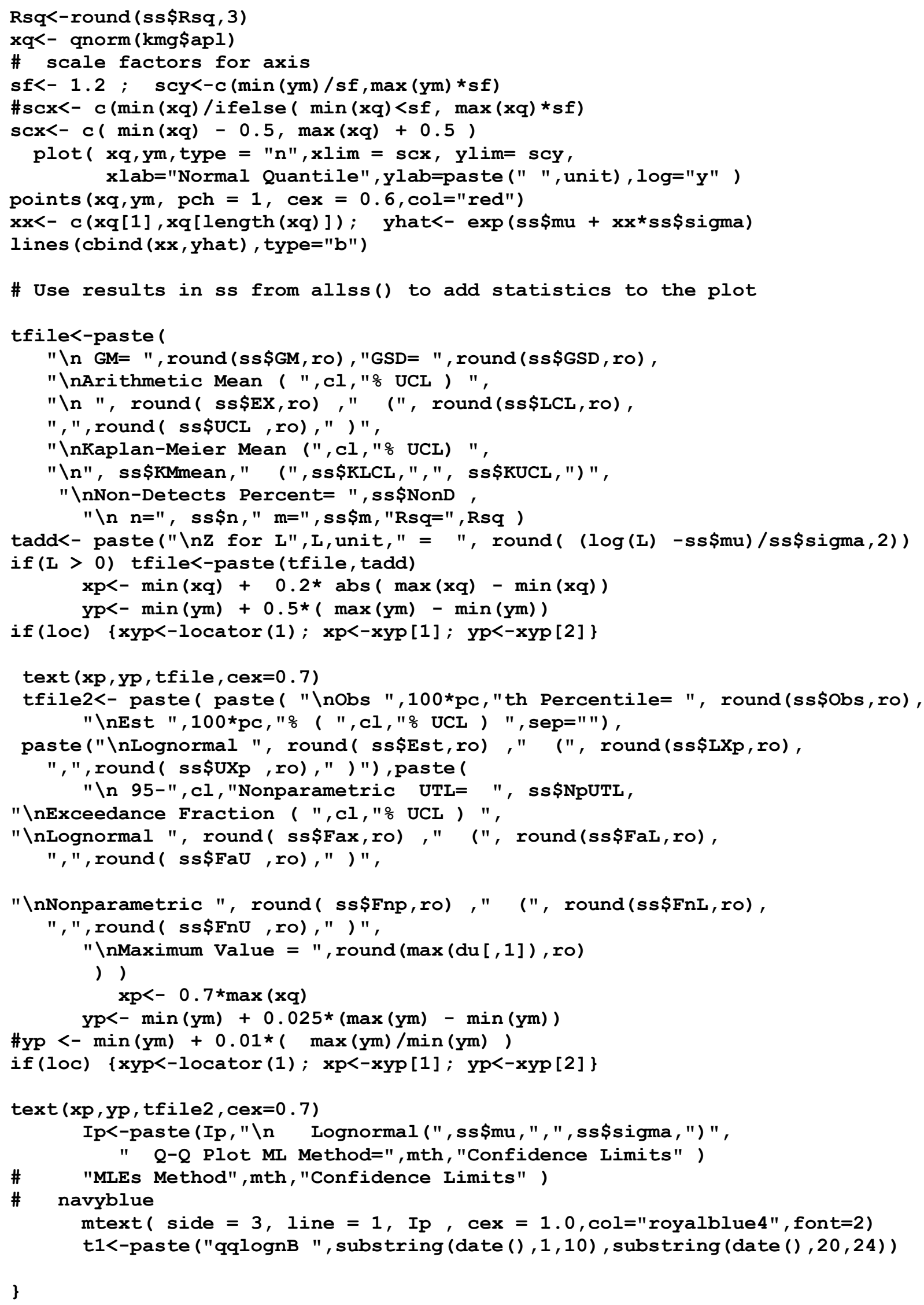




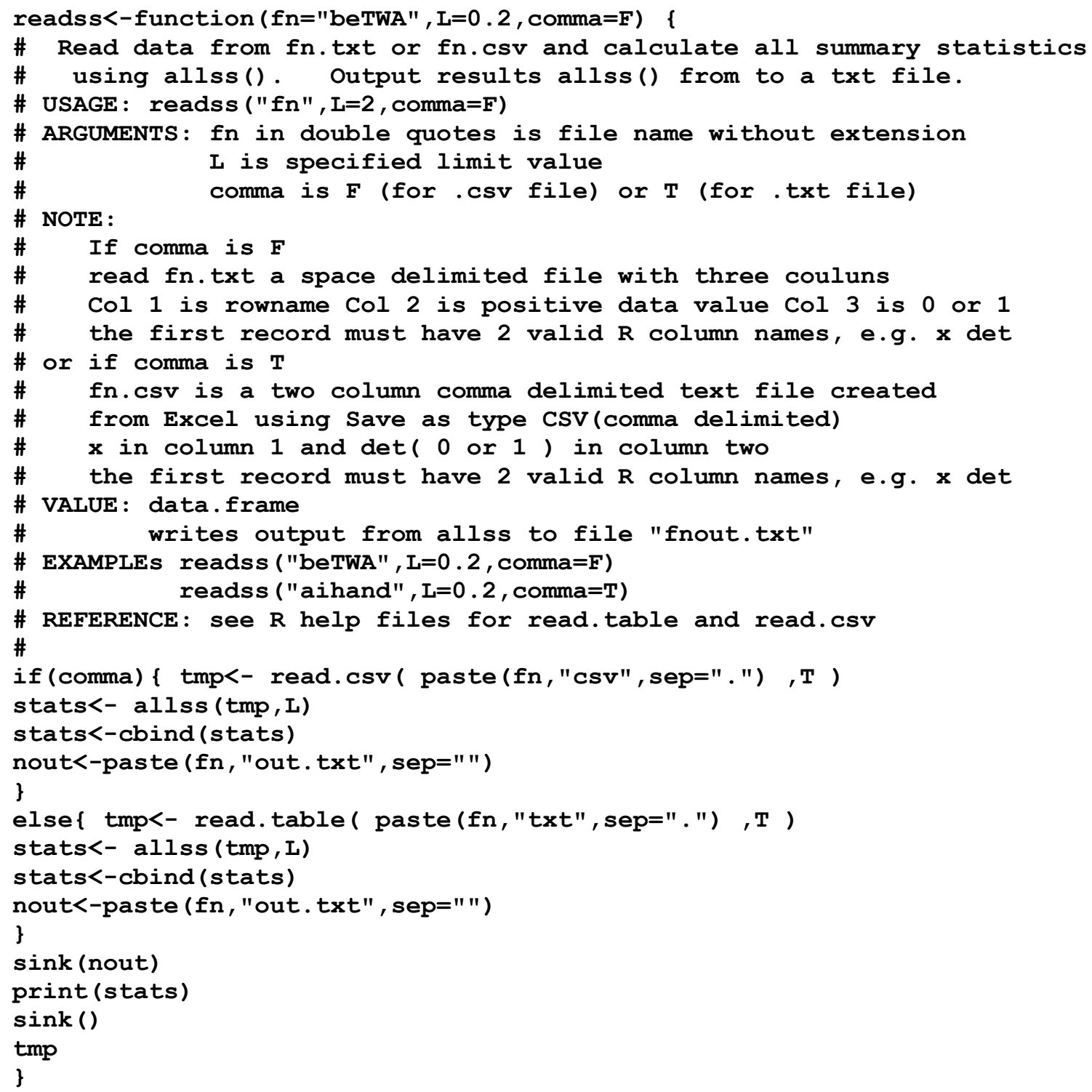




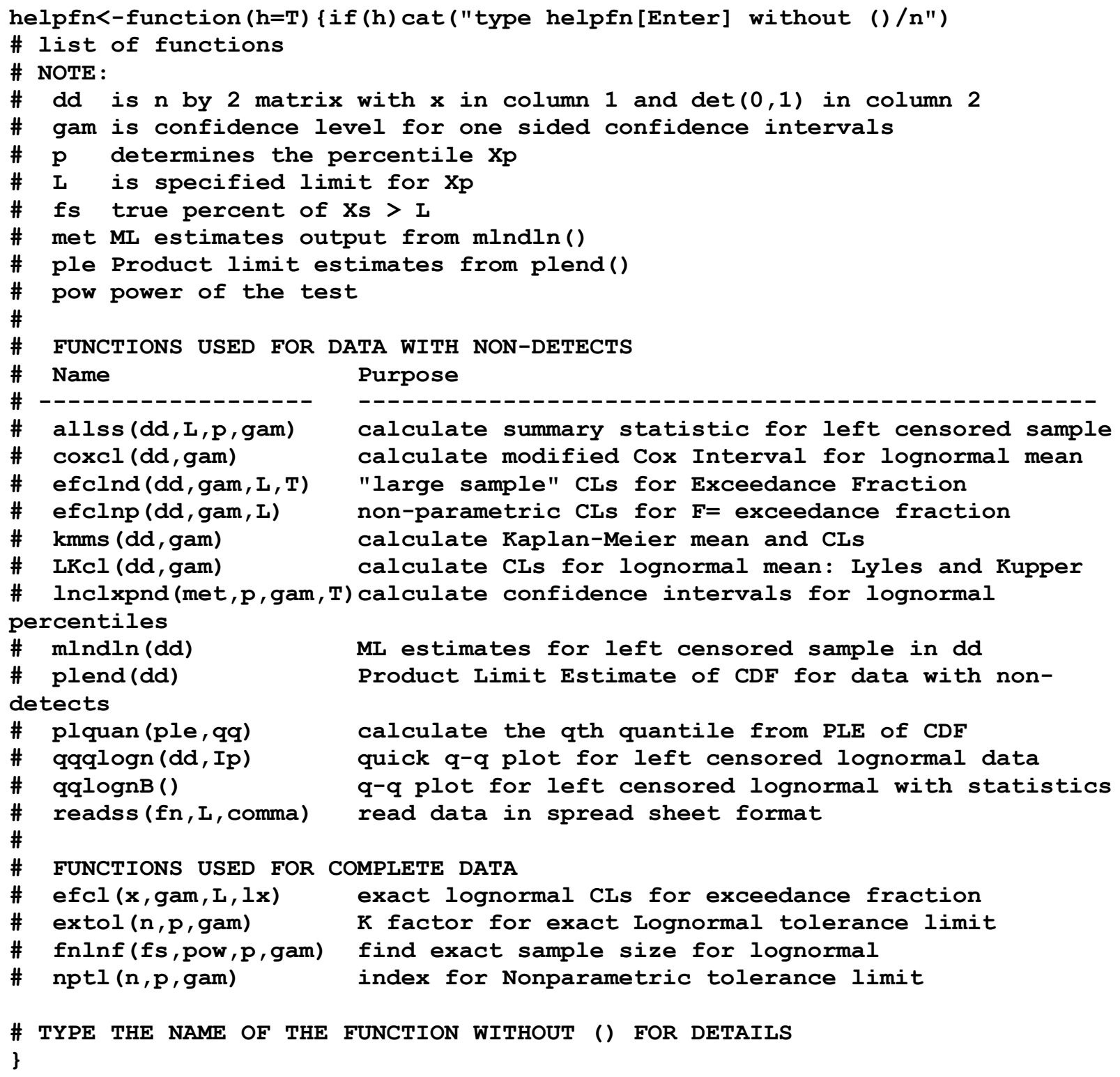




\section{DISTRIBUTION LIST}

\section{Internal}

1. E. L. Frome

2. J.A. Nichols

3. T. Zacharia

4. ORNL Central Research Library

5. ORNL Laboratory Records - RC

6-7. ORNL Laboratory Records - OSTI

Electronic Notification

8. C. Strader ( $\underline{\text { Cliff.Strader@eh.doe.gov) }}$

9. W. Tankersley (TankersB@orau.gov)

10. P. Wambach (Paul.Wambach@eh.doe.gov)

11. D. Weitzman (David.Weitzman@eh.doe.gov) 